A heuristic approach to rapid, automatic identification of uranium in high-resolution gamma-ray spectra

T. Gosnell

April 30, 2013 
This document was prepared as an account of work sponsored by an agency of the United States government. Neither the United States government nor Lawrence Livermore National Security, LLC, nor any of their employees makes any warranty, expressed or implied, or assumes any legal liability or responsibility for the accuracy, completeness, or usefulness of any information, apparatus, product, or process disclosed, or represents that its use would not infringe privately owned rights. Reference herein to any specific commercial product, process, or service by trade name, trademark, manufacturer, or otherwise does not necessarily constitute or imply its endorsement, recommendation, or favoring by the United States government or Lawrence Livermore National Security, LLC. The views and opinions of authors expressed herein do not necessarily state or reflect those of the United States government or Lawrence Livermore National Security, LLC, and shall not be used for advertising or product endorsement purposes.

This work performed under the auspices of the U.S. Department of Energy by Lawrence Livermore National Laboratory under Contract DE-AC52-07NA27344. 


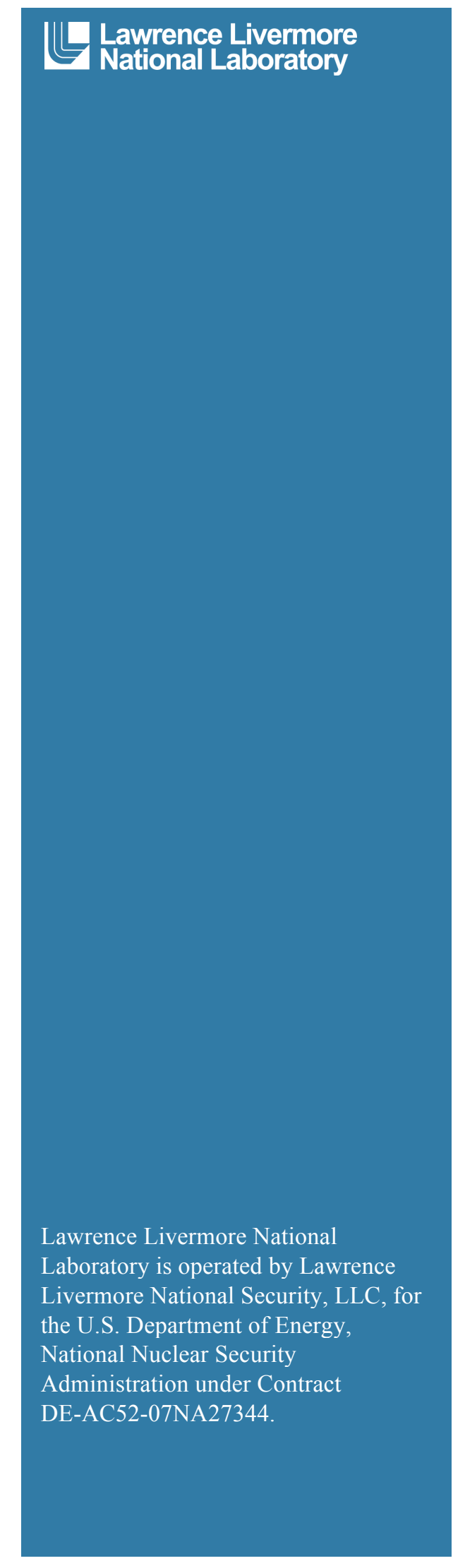

\section{A heuristic approach to rapid, automatic identification of uranium in high-resolution gamma-ray spectra}

Thomas B. Gosnell

April 2013

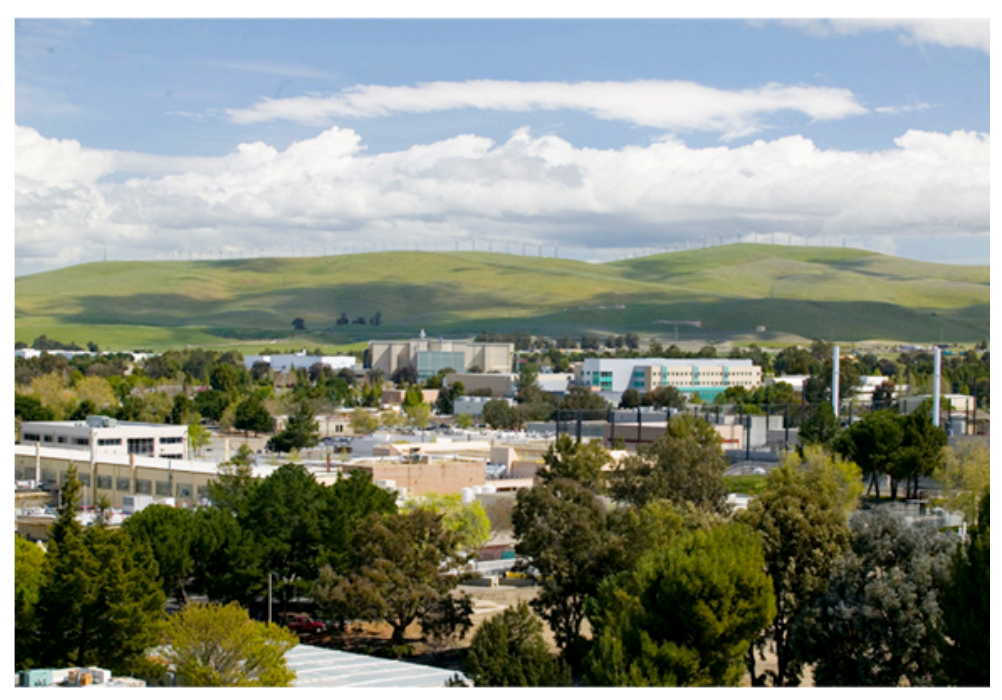




\section{Disclaimer}

This document was prepared as an account of work sponsored by an agency of the United States government. Neither the United States government nor Lawrence Livermore National Security, LLC, nor any of their employees makes any warranty, expressed or implied, or assumes any legal liability or responsibility for the accuracy, completeness, or usefulness of any information, apparatus, product, or process disclosed, or represents that its use would not infringe privately owned rights. Reference herein to any specific commercial product, process, or service by trade name, trademark, manufacturer, or otherwise does not necessarily constitute or imply its endorsement, recommendation, or favoring by the United States government or Lawrence Livermore National Security, LLC. The views and opinions of authors expressed herein do not necessarily state or reflect those of the United States government or Lawrence Livermore National Security, LLC, and shall not be used for advertising or product endorsement purposes. 


\section{Table of Contents}

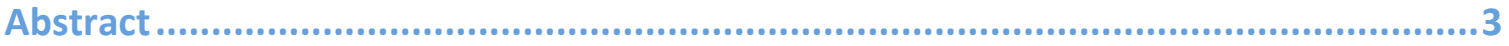

Introduction ..................................................................................................

Rapid automatic nuclide identification...................................................... 4

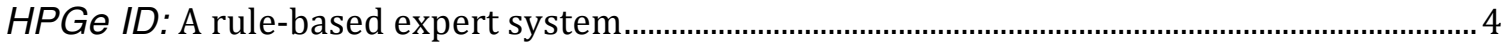

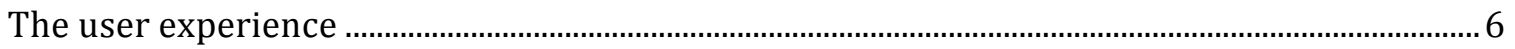

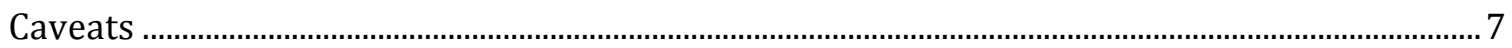

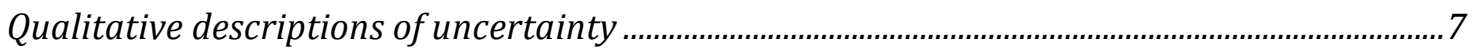

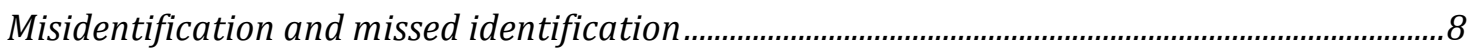

Advantages and disadvantages of expert systems ....................................................................

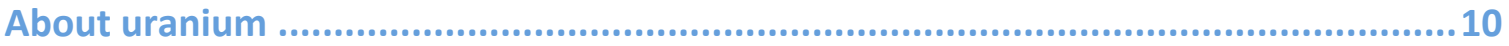

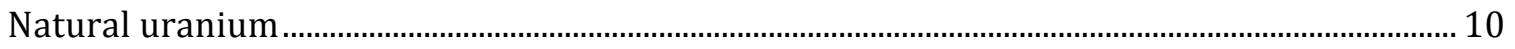

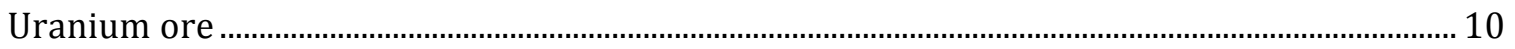

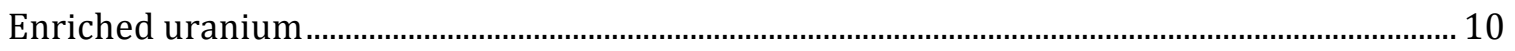

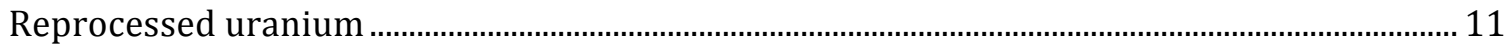

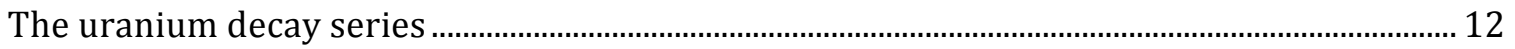

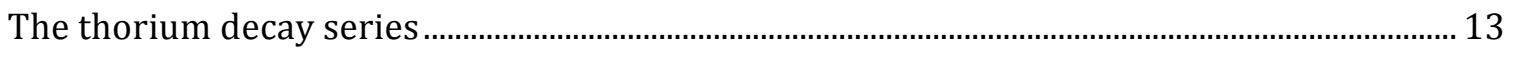

Thorium-228: Nexus nuclide-a ubiquitous and ambiguous signature ......................................... 13

Fluorine in uranium - Uranium hexafluoride and uranyl fluoride ............................................ 14

The uranium contribution to background spectra........................................................................... 15

More observations about background interference in field measurements .............................. 17

Detecting the presence of uranium ...................................................... 18

Key full-energy peaks from uranium isotopes and collateral nuclides ......................................... 18

Uranium-235-The only fissile primordial nuclide: .................................................................... 19

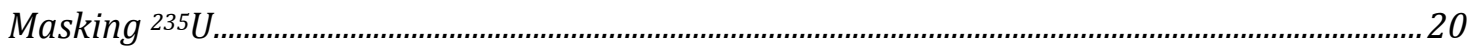

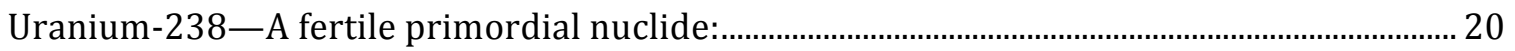

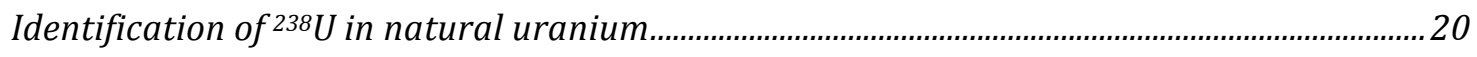

Uranium-234-Naturally occurring, not primordial-another decay series nexus ................. 21

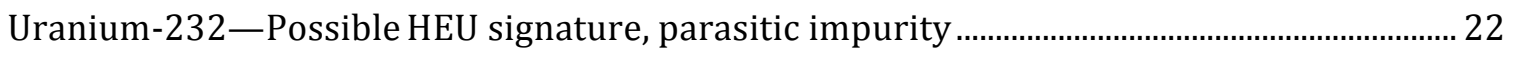

Uranium-233-Looking to the future and the thorium fuel cycle ................................................ 22

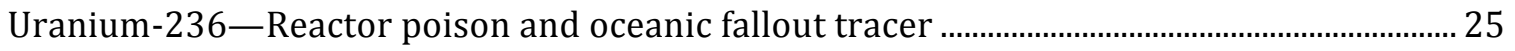

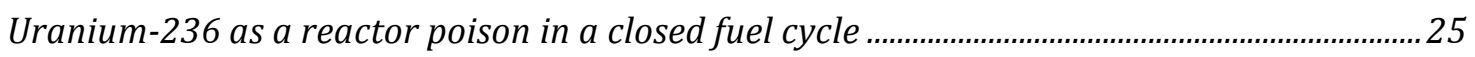

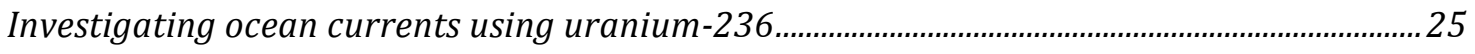

Uranium-237- Fissions with fast neutrons, production of heat-source ${ }^{238} \mathrm{Pu}$........................... 25

Estimating uranium enrichment............................................................. 26

Minimum enrichment estimation by peak-area ratio...................................................................... 26

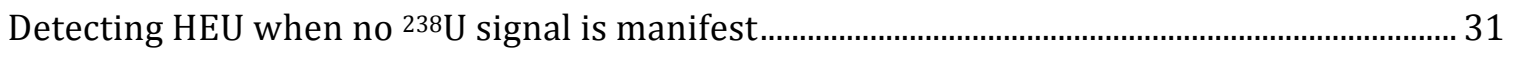

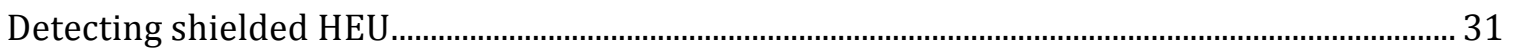


Uranium-232: grasping at straws to detect shielded HEU ..........................................................

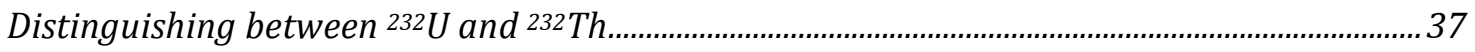

Further distinguishing between natural $U$ and processed U............................. 39

The 609/1001 peak-area ratio ..................................................................................................... 39

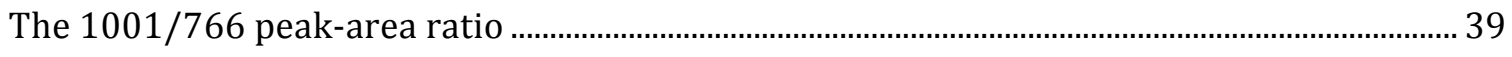

Uranium-232 and apparent uranium-238 in plutonium ............................... 41

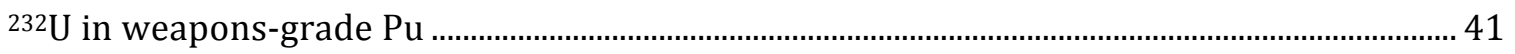

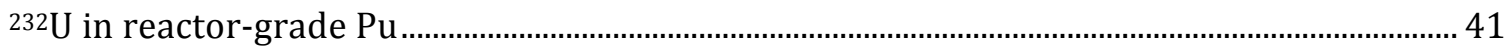

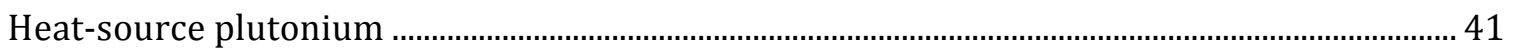

Plutonium-238-Plutonium masquerading as $238 \mathrm{U}$...................................................................... 42

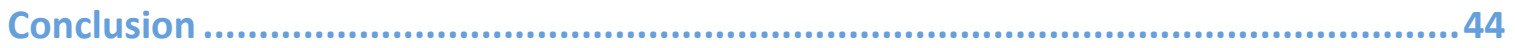

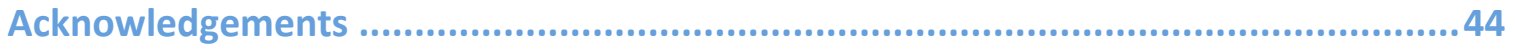

Appendix: Signal-to-noise ratio computation ............................................. 45

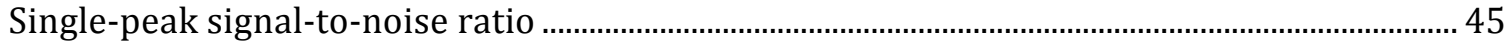

Effective signal-to-noise ratios for provisional nuclide identification .......................................... 47

Effective signal-to-noise ratio for individual findings .................................................................... 48

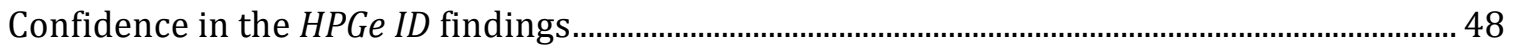

References............................................................................................ 49 


\title{
A heuristic approach to rapid, automatic identification of uranium in high-resolution gamma-ray spectra
}

\author{
Abstract \\ Our rule-based expert system, $H P G e I D$, is used to rapidly and automatically identify well \\ over 200 radioactive sources in less than one second from their gamma-ray signatures in \\ high-resolution gamma-ray spectra. One of the most important sources, uranium, is the \\ most complex in terms of natural or processed form, enrichment grade, and even reactor \\ fuel cycle. To determine these attributes, HPGe ID does not require knowledge of the \\ detector efficiency, the source-to-detector distance, or the geometry of the inspected \\ radiation source-including any shielding. Here we discuss the approach taken with \\ HPGe ID to detect and determine these uranium attributes.
}

\section{Introduction}

Every gamma-ray spectrum tells a story and, like a book, it can be read if you understand the language. A book in good condition with crisp print can be easily read. A book in poor condition, such as a tattered ancient biblical scroll with voids in the document, can only be read with imprecision. Similarly, a gamma-ray spectrum acquired in the field for a brief period of time and smeared by a detector with poor energy resolution is likely to be read with similar imprecision, sometimes resulting in nuclide misidentification [1].

Gamma-ray spectra collected by nuclear incident first responders are obtained in the field, usually under suboptimal conditions, for short periods of time, and can result in sparse data that cannot reveal the finest details. Nevertheless, the superior energy resolution of HPGe spectra provides considerably greater information content than is found in commonly employed scintillation detectors, such as NaI(Tl) [1]. For this reason, HPGe excels in the analysis of complex spectra from sources of mixed radionuclides [2] such as uranium. This is true even for spectra from high-resolution detectors where only the most intense gamma-ray full-energy peaks can regularly be observed with confidence.

Even under these conditions, one can frequently, with reasonable confidence, exploit the energy resolution of HPGe to detect uranium, discriminate between natural and processed uranium, and obtain a rough estimate of minimum uranium enrichment. In this paper we describe our approach to achieving these goals for uranium with HPGe ID, a rule-based system that assists the gamma-ray spectrometrist with rapid analytical results (in about one second) for uranium and the wide variety of other radionuclides that can be found in commerce. 


\section{Rapid automatic nuclide identification}

\section{HPGe ID: A rule-based expert system}

Excellent quantitative computer programs for automated laboratory analysis of highresolution gamma-ray spectra from samples of known provenance have been in existence for nearly half a century. In contrast, our computer code, HPGe ID performs qualitative analyses. It must be able to successfully apply heuristics to analyze field spectra from a large number of nuclides and mixed sources of nuclides, taken with HPGe detectors of widely varying and uncertain efficiency. Though not originally developed as an expert system, HPGe ID now contains all of the classic features of an expert system.

The radioactive items to be measured are usually in containers of widely varying size and unknown construction. The containers lightly or heavily shield the item, attenuating and scattering its radiation before it reaches the detector. The spectra are taken at source-todetector distances that are varied and usually inexact and spectral data are typically acquired for only a relatively short duration.

Because of the nature of field spectra and the heuristic nature of radionuclide identification and characterization, we have chosen to implement HPGe ID as a rule-based expert system $[3,4]$, a knowledge-based approach rather than a strictly procedural approach. As experience with these field spectra deepens, we need to incorporate newly gained knowledge of their characteristics in a painless manner. An expert system differs from traditional programs by having a unique structure. It is modular, divided into two parts: a knowledge base or rule base that can be easily modified or expanded and an inference engine that remains fixed and reasons from the knowledge base in much the same manner as a human expert.

Another characteristic of expert systems is that they are heuristic-like humans they reason with expert judgmental knowledge, rules of thumb, as well as formal established knowledge. As such HPGe ID follows the typical reasoning process used by gamma-ray spectrometrists. Here we sketch elements of HPGe ID that are characteristic of expert systems as applied to nuclide identification.

- User interface: HPGe ID employs a graphical user interface expressed in two windows, augmented by a third utility window for energy calibration adjustment.

- Feature extraction: The code extracts a number of features such as the presence or absence of key peaks, their net counts, regions of interest, and ratios. These features form the working database examined by a binary decision tree that evaluates which of several hundred potential results fit a particular sample.

- Explanation facility: An explanation facility ideally can present a chain of reasoning that led to a certain conclusion. HPGe ID does log the execution of the rule set for each analysis that is an essential tool for debugging the knowledge base but is sufficiently complex, arcane, and tedious to be of no value to the spectrum analyst who requires a rapid preliminary physics analysis. Instead, the user interface provides graphical and textual information that aids the experienced analyst in determining the validity of the 
conclusions or if they are mistaken. Of greatest importance, spectral templates are available for comparison to candidate nuclides or complex sources, such as uranium, for comparison to the unknown spectrum for line matching. Additionally, the knowledge domain of HPGe ID encompasses some rarely encountered radionuclides that may be unfamiliar to the analyst. Spectral information is rarely context free. The user interface provides source usage information, which combined with contextual information provided with the spectrum, can provide analytical confidence. For example, if a radiation source appears to be within a person who claims to have had medical radiation treatment and HPGe ID identifies it as ${ }^{67} \mathrm{Ga}$, the usage pane provides the following information: $3.2612 \mathrm{~d}$ half-life, Used in humans for imaging of abdominal infections, (...) Can be detected for 2-3 weeks.

- Knowledge base: A rule-based system is a knowledge-based system where the knowledge base is represented in the form of a set of rules. Rules are an elegant, expressive, straightforward, and flexible means of expressing knowledge [4]. Facts in the form of IF-THEN-ELSE yield Boolean values that can become conditions for use by rules that follow in the decision tree, leading to swift execution. For example, fundamental facts include the existence of key gamma-ray lines, line ratios with thresholds, and integrated counts in selected spectrum energy regions.

- Inference engine: Coding that decides which facts are germane to the analysis, which rules are satisfied by these facts, and executes the rules. Typically, the presence of a nuclide will be reported when line combinations for that nuclide are present and, usually, some further conditions must be satisfied to prevent nuclide misidentification and to report additional findings beyond simple nuclide identification.

- Findings: The inference engine prepares a list of findings, prioritized by effective signal-to-noise ratio (defined in the appendix). The rules that generate the list must be satisfied by the facts in the working database. Once the inference engine establishes that all of the conditions in a rule and its antecedents are satisfied, it then adds the rule to its appropriate rank in the findings to be reported once the journey through the rule set reaches a conclusion.

Fig. 1 is a block diagram showing the relationships between the expert system's elements.

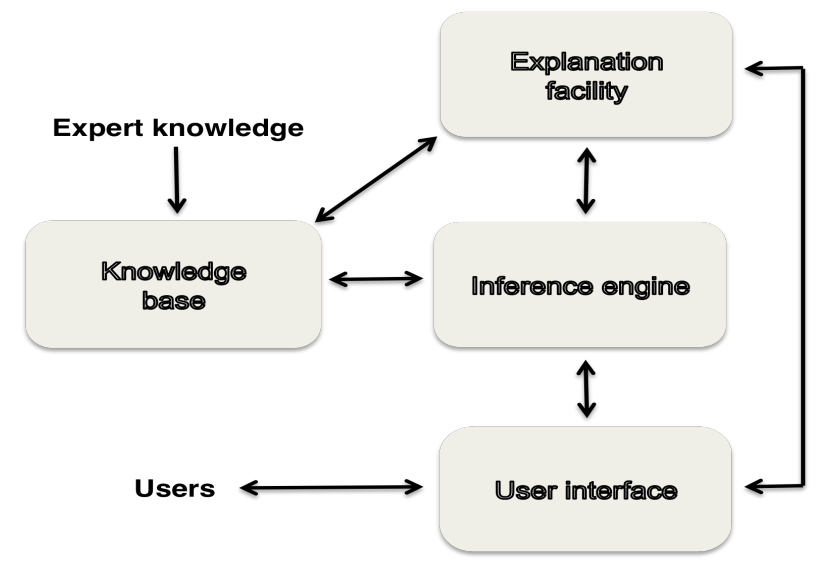

Fig. 1. Expert system block diagram 


\section{The user experience}

Launching HPGe ID reveals its primary window. An example is shown in Fig. 2.

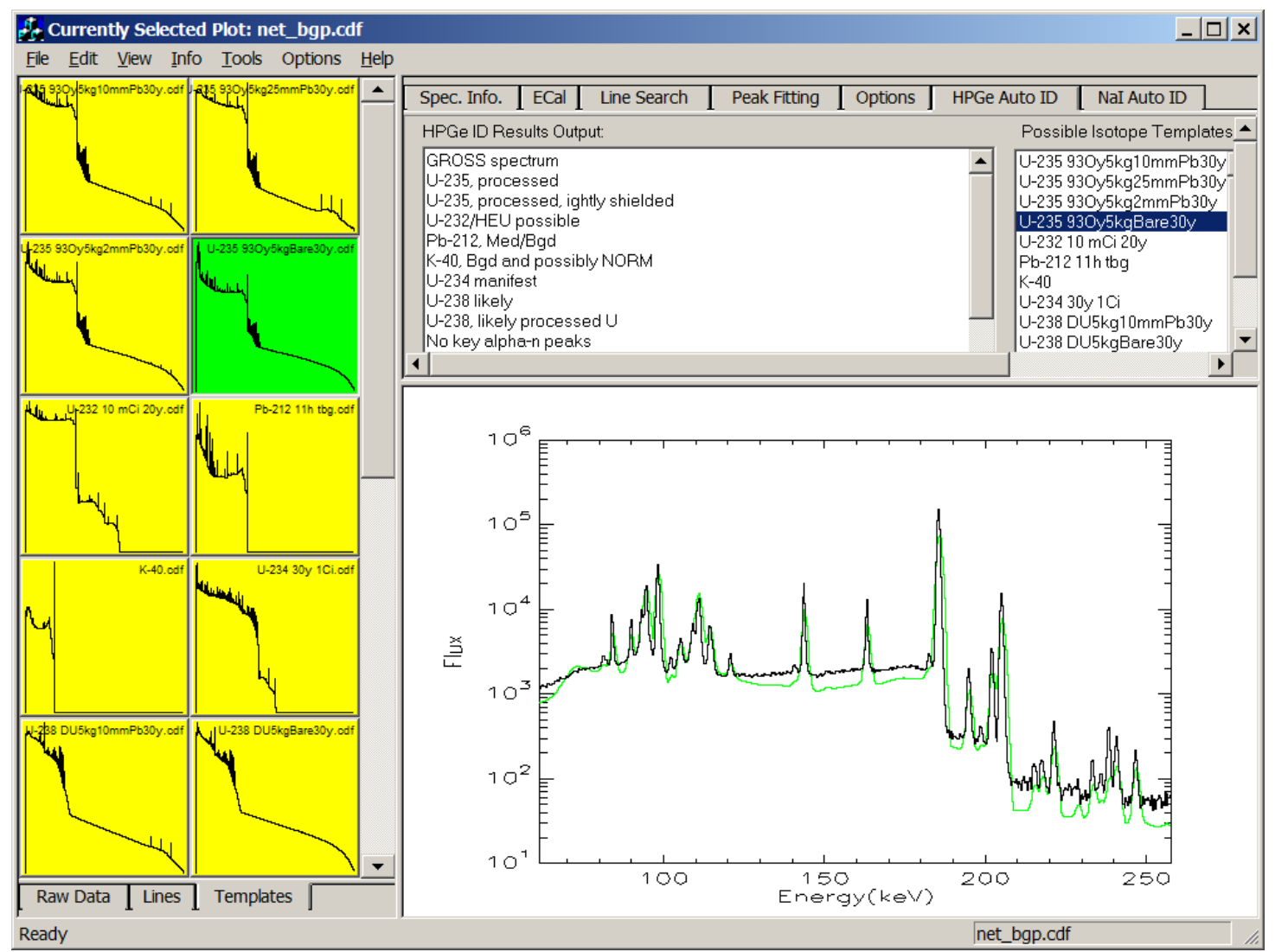

Fig. 2. The HPGe ID primary window. In this figure, the user has dragged and dropped a spectral data file in the pulse-height analyzer's proprietary format into the primary viewer pane. HPGe ID translated the proprietary format into a common internal format and displays it in the primary viewer pane. Abbreviated and prioritized result findings appeared in the upper middle pane, indicating that the spectrum is from weapons-grade uranium, and a number of candidate spectral templates appeared in the upper right-hand pane for the user to compare with the data. Spectral thumbnails of the candidates are on the left-hand side, shown in yellow, with the exception of the currently displayed template shown as a green thumbnail. These events unfolded within less than one second. The user has since zoomed the primary view to the first $250-\mathrm{keV}$ of the spectrum and sampled a variety of candidate templates for comparison to the measured data, finally settling on a template of unshielded $93 \%{ }^{235} \mathrm{U}$, shown in green.

Most user analyses are for benign sources with commonly encountered radionuclides such as medical ${ }^{99 \mathrm{mTc}}$ or Naturally Occurring Radioactive Material (NORM and TENORM (Technologically Enhanced NORM) [5, 6, 7]). For these spectra, the results in the Primary window may well suffice. For unusual or complex data, additional information can be obtained from the Details window chosen from the menu bar in the primary window. Fig. 3 shows the Details window. 


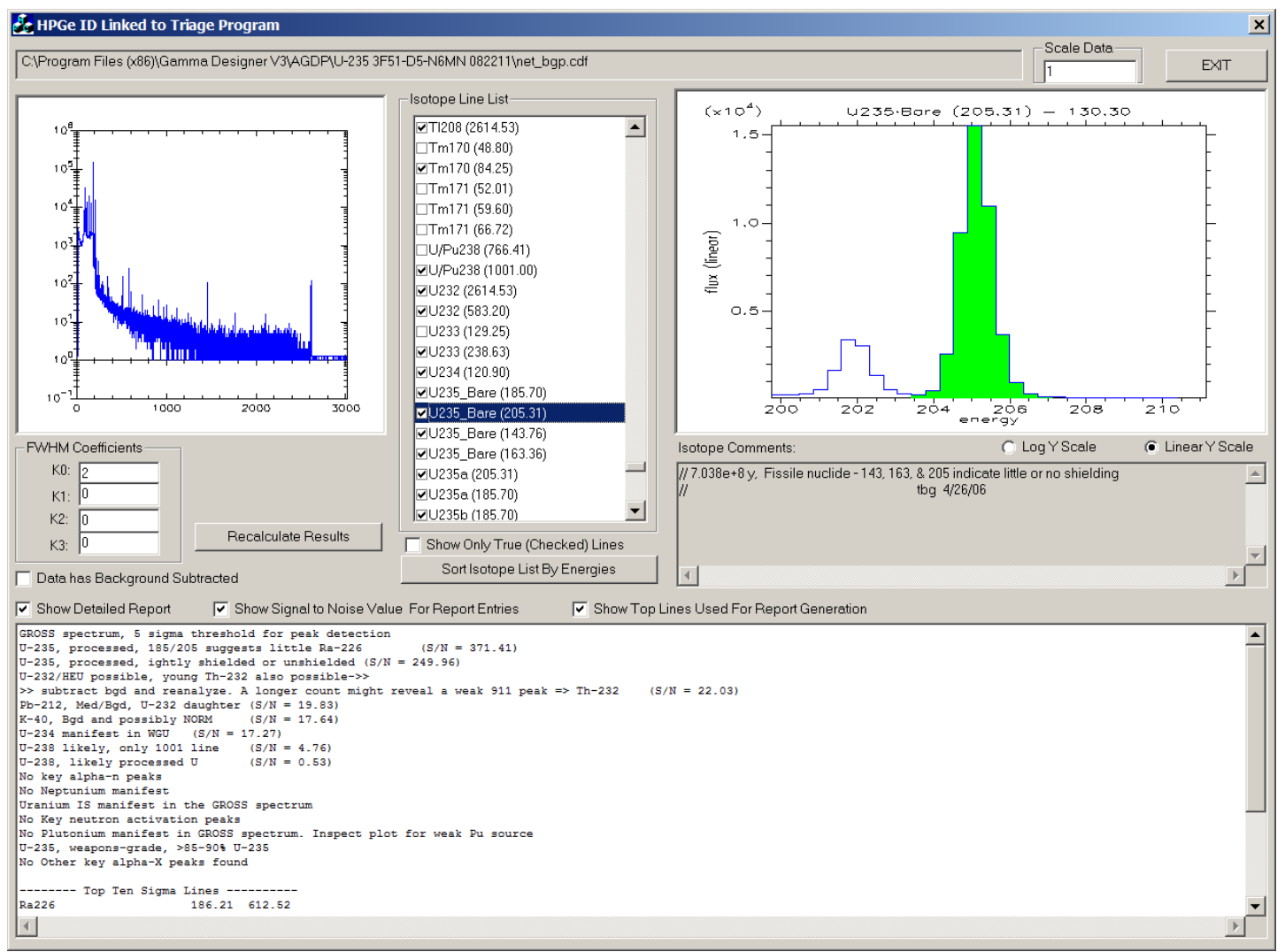

Fig. 3. The HPGe ID Details window. In this figure the detailed findings appear in the bottom pane. These include expanded textual results from the primary window. They are prioritized by descending effective signal-to-noise ratio, $\mathrm{S} / \mathrm{N}$, as defined in the Appendix. Finally, they are followed by summary results indicating the presence or absence of uranium, plutonium, neptunium, common neutron activation activity, common alpha-n activity, and other common alpha-x activity. A thumbnail display of the entire spectrum appears in the upper left pane. The upper center window reveals the 600+ lines that HPGe ID searches for and lists them alphabetically by associated element and mass number. Small boxes to the left of the line descriptions contain checks if the line is an initial candidate for identification. Below this window is a button that will re-sort the lines by gamma-ray energy. A close-up single-line view is shown in the upper right pane for the $205-\mathrm{keV}^{235} \mathrm{U}$ line, chosen by the user from the isotope line list. The green shading indicates the spectral region used for identification of this peak. Below the line-view pane is a description of the nuclide's provisional identification, its halflife, categorization (e.g. medical, industrial, fissile, research, or impurity) and, usually, its uses/applications or other raison d'être.

\section{Caveats}

\section{Qualitative descriptions of uncertainty}

Problem solving concerns the search for a solution. The principal role of the inference engine is to search for the most appropriate item of knowledge at a given moment [4]. For HPGe ID, achieving search efficiency necessitated the reliance on heuristics. 
"A heuristic is a rule of thumb, strategy, trick, simplification, or any other kind of device which drastically limits search for solutions in large search spaces. [8]."

When we report out the findings, some of the rules can produce results of dubious certainty or, on occasion, incorrect results. HPGe ID is now sufficiently mature that unrecognized incorrect results have become increasingly rare. When dubious results occur and are recognized by the inference engine, we indicate a subjective judgment of uncertainty in the rule findings report. This may be expressed as a word or one or more question marks:

- No caveat $\Rightarrow$ near certainty

- Likely

- Probable

- ? $\quad \Rightarrow$ Possible

- ?? $\quad \Rightarrow$ Doubtful

- ??? $\quad \Rightarrow$ Very doubtful

\section{Misidentification and missed identification}

The HPGe ID inference engine begins its search by looking for key candidate full-energy peaks. To become candidates, peaks must be very close in energy, according to the spectrum energy calibration, to key peaks of interest and strong enough to be declared manifest by exceeding a prescribed signal-to-noise threshold as defined in the Appendix. The threshold setting is a compromise set high enough to minimize excessive false peak presence identification and low enough to capture most peaks of interest. Because HPGe ID does not have the visual peak recognition capability, or the contextual awareness of an experienced gamma-ray spectrometrist, it will occasionally fail to identify the presence of weak peaks that would be obvious to the spectrometrist's eye.

We have specified the energies of over 600 peaks for identifying more than 200 sources. In spite of the high resolution of HPGe, multiple peak energies, especially at low energies, can fall within the resolution width of the detector. For example, in Fig. 3 the green shading at the base of the peak in the peak window defines the resolution width for the $205-\mathrm{keV}$ peak from ${ }^{235} \mathrm{U}$. Not shown in the figure is the tentative identification of the $204.1-\mathrm{keV}$ peak from medical ${ }^{255} \mathrm{Fm}$ as well as the $204.12-\mathrm{keV}$ peak from fission product and medical ${ }^{25} \mathrm{Nb}$. Moreover, complex spectra, such as from plutonium, will have gamma-ray lines that are sufficiently close to many of the $600+$ key lines, that they become candidate peaks.

Bogus candidate peaks begin to be winnowed out with the search for candidate nuclides that usually require the presence of two or more candidate peaks. Further winnowing is typically required to achieve nuclide identification by attaching additional conditions, such as appropriate ratios of the areas of winnowed peaks. Attributes associated with nuclides, for example uranium enrichment estimates, require nuclide identification followed by additional conditions.

Good spectral energy calibration is essential for HPGe ID to produce useful results. Application of HPGE ID to a poorly calibrated spectrum will invariably produce a hodgepodge of fantasy identification results. Although HPGe ID possesses an energy calibration capability, chosen by the ECal tab shown in Fig. 2, highly precise energy 
calibration over a wide energy range cannot be expected of the spectra presented to HPGe ID. Therefore HPGe ID is necessarily forgiving of small errors in energy calibration, even though such errors exacerbate the peak identification search.

Missing legitimately present nuclides is a much smaller problem than misidentification. It can, however, occur when weak sources are present. To limit the number of radioactive sources that HPGe ID has to address, we have concentrated on those likely to be found in commerce with a primary focus on identifying illicit fissile material. Within these boundaries, HPGe ID has evolved into a useful tool that continues to be refined.

\section{Advantages and disadvantages of expert systems}

Expert systems are designed to operate within a narrow, well-defined domain of knowledge. Their advantages include:

- Creation of efficiencies and reduction of the time needed to analyze a spectrum,

- A modular database of expert knowledge that is independent of the inference engine and is more easily modifiable than conventional programs,

- Within the domain of the knowledge base, a different problem can be solved using the same program without reprogramming efforts,

- The ability to reason heuristically. The human mental process is internal, and it is too complex to be represented as an algorithm. However, most experts are capable of expressing their knowledge in the form of rules for problem solving.

Expert system disadvantages include:

- Lack of common sense. For example, expert systems have difficulty in recognizing domain boundaries. When given a task different from the typical problems (for example when a complex and unusual unknown spectrum, such as mixed nuclear waste, is presented to HPGe ID), an expert system might attempt to solve it and fail in rather unpredictable ways,

- Lack of creativity. Human experts can respond creatively to unusual situations, expert systems cannot,

- Problems with excessive scope expansion of the knowledge base: for example adding new nuclides in $H P G e I D$, can create conflicts with existing rules, increasing the difficulty of knowledge-base maintenance,

- To err is human. Even a brilliant expert is only a human and thus can make mistakes. This suggests that an expert system built to perform at a human expert level should also be expected to make occasional mistakes. Errors and omissions in the knowledge base can lead to incorrect findings. Expanding and debugging the HPGe ID knowledge base has been in progress for nine years. It is now valued by its users but still remains a work in progress. Remaining errors in its conclusions have proven to be readily detectable by its users-experienced gamma-ray spectrometrists, experts themselves. As such, HPGe ID is a tool to assist experienced gamma-ray spectrometrists, not replace them. It provides rapid preliminary results for the analyst but is not a tool intended for use by those unfamiliar with gamma-ray spectrometry. 


\section{About uranium}

Volumes have been written about uranium. Here we concentrate on those aspects of uranium that can be revealed by rapid automatic nuclide identification and attribution by high-resolution gamma-ray spectrometry.

\section{Natural uranium}

Uranium is a primordial radioactive element found in trace amounts in all rocks and soil, in water and air, and in materials made from natural substances. Nevertheless, it is one of the more common elements in the Earth's crust, roughly some 40 times more common than silver and 500 times more common than gold $[9,10,11]$.

Uranium appears naturally in the form of a vector of three isotopes, ${ }^{234} \mathrm{U},{ }^{235} \mathrm{U}$, and ${ }^{238} \mathrm{U}$. By mole fraction their natural isotopic abundances are $0.000054(5)$ for ${ }^{234} \mathrm{U}, 0.007204$ (6) for primordial $235 \mathrm{U}$, and $0.992742(10)$ for primordial ${ }^{238} \mathrm{U}[12]$ but variation does exist in uranium isotope ratios (for example, [13]). Uranium-234 is not primordial but appears as one of the decay daughters of ${ }^{238} \mathrm{U}$.

\section{Uranium ore}

While uranium typically occurs in trace amounts in the earth's crust, it is also found concentrated in a range of minerals $[14,15,16]$. Some are quite beautiful and a few are found in extensive deposits that are economically recoverable-these are the uranium ores.

Uranium occurs in nature as a mixture of numerous uranium oxides. The most common forms of uranium oxide are triuranium octaoxide $\left(\mathrm{U}_{3} \mathrm{O}_{8}\right)$ and uranium dioxide $\left(\mathrm{UO}_{2}\right)$. Triuranium octaoxide is the most common form found naturally and can remain in the soil for thousands of years without moving downward into groundwater [17]. Both oxide forms are solids, have low solubility in water, and are relatively stable over a wide range of environmental conditions.

Unsurprisingly, both triuranium octaoxide and uranium dioxide are commonly found in uranium ores $[18,19]$. The two primary uranium ores are uraninite and pitchblende. Uraninite contains both $\mathrm{UO}_{2}$ and $\mathrm{U}_{3} \mathrm{O}_{8}$, with $\mathrm{UO}_{2}$ dominating. Uraninite usually forms black, gray, or brown crystals that are moderately hard and generally opaque. A variety of uraninite ore that is dense and found in granular masses with a greasy luster is called pitchblende, in witch $\mathrm{U}_{3} \mathrm{O}_{8}$ dominates [20].

\section{Enriched uranium}

When processed, uranium is chemically purified, removing the daughters of $235 \mathrm{U}$ and $238 \mathrm{U}$, except for its ${ }^{234} \mathrm{U}$ daughter. Processed uranium is typically enriched in the isotopic fraction of ${ }^{235} \mathrm{U}$. If not enriched, the processed uranium can be made into heavy-water reactor fuel. It will have retained its natural isotopic vector and, although processed, is confusingly referred to as natural uranium (NU). The tailings of the enrichment process, depleted uranium (DU), are reduced in their ${ }^{235} \mathrm{U}$ content. Uranium enrichment grades are shown in Table 1. 
Table 1. Uranium enrichment grades

\begin{tabular}{lll}
\hline Grade & Percent $235 \mathrm{U}$ & Typical uses \\
\hline Depleted uranium (DU) & $<0.711[21]$ & $\begin{array}{l}\text { Radiation shielding, armor- } \\
\text { piercing bullets, ballast }\end{array}$ \\
Natural uranium (NU) & $0.711[21]$ & $\begin{array}{l}\text { Heavy-water reactor fuel } \\
\text { Low-enriched uranium (LEU) }\end{array}$ \\
$\begin{array}{l}\text { Highly enriched uranium } \\
\text { (HEU) }\end{array}$ & $>20 \%[21]$ & $\begin{array}{l}\text { Light water reactor fuel } \\
\text { Naval and fast neutron } \\
\text { reactor fuel, medical } \\
\text { radionuclide production }\end{array}$ \\
Weapons-grade uranium & $>85-90 \%[22,23]$ & $\begin{array}{l}\text { Nuclear explosives, Naval } \\
\text { reactor fuel [24] }\end{array}$ \\
(WGU) & &
\end{tabular}

\section{Reprocessed uranium}

Reprocessed uranium (RepU) is the uranium recovered from nuclear reprocessing, as done commercially in France, the UK, Japan, and by nuclear weapons states' military plutonium production programs. This uranium actually makes up the bulk of the material separated during reprocessing. Commercial light-water reactor spent fuel contains on average (excluding cladding only four percent plutonium, minor actinides, and fission products by weight. Reuse of reprocessed uranium has not been common because of low prices in the uranium market of recent decades, and because it contains undesirable isotopes of uranium [25].

During its irradiation in a reactor, uranium is profoundly modified. The uranium that leaves the reprocessing plant contains all the isotopes of uranium between ${ }^{232} \mathrm{U}$ and $238 \mathrm{U}$. Uranium237 , with only a 6.75 -day half-life, decays rapidly to ${ }^{237} \mathrm{~Np}[26]$.

The composition of reprocessed uranium depends on the initial enrichment and the time the fuel has been in the reactor [27]. A typical vector of uranium isotopes in reprocessed uranium, with attributes, is listed in Table 2.

Table 2. Typical isotopic vector of reprocessed uranium [25]

\begin{tabular}{llll}
\hline Isotope & Proportion $(\%)$ & Half-life & Characteristics \\
\hline${ }^{238} \mathrm{U}$ & 99 & $4.47 \mathrm{e} 9 \mathrm{y}$ & Fertile material \\
${ }^{237} \mathrm{U}$ & $\sim 0.001$ & $6.75 \mathrm{~d}$ & Decays rapidly to ${ }^{237} \mathrm{~Np}$ \\
${ }^{236} \mathrm{U}$ & $0.4-0.6$ & $2.34 \mathrm{e} 7 \mathrm{y}$ & Neutron absorption lowers reactivity, also produces ${ }^{237} \mathrm{~Np}$ \\
${ }^{235} \mathrm{U}$ & $0.4-0.8$ & $7.04 \mathrm{e} 8 \mathrm{y}$ & Fissile material \\
${ }^{234} \mathrm{U}$ & $>0.02$ & $2.46 \mathrm{e} 5 \mathrm{y}$ & Fertile material, neutron absorption increases reactivity \\
${ }^{233} \mathrm{U}$ & trace & $1.59 \mathrm{e} 5 \mathrm{y}$ & Fissile material \\
${ }^{232} \mathrm{U}$ & trace & $68.9 \mathrm{y}$ & Decay product ${ }^{208} \mathrm{Tl}$ emits strong gamma radiation making \\
& & & handling difficult \\
\hline
\end{tabular}

1 This designation is an unofficial subset of HEU but is in widespread use. 


\section{The uranium decay series}

The radiation signatures of natural and processed uranium in gamma-ray spectra can be understood and distinguished by the decay of ${ }^{238} \mathrm{U}$ and, importantly, by its radioactive daughters. Uranium-238 is the progenitor of a long radioactive decay series. A diagram with the main features of the uranium series is shown in Fig. 4.

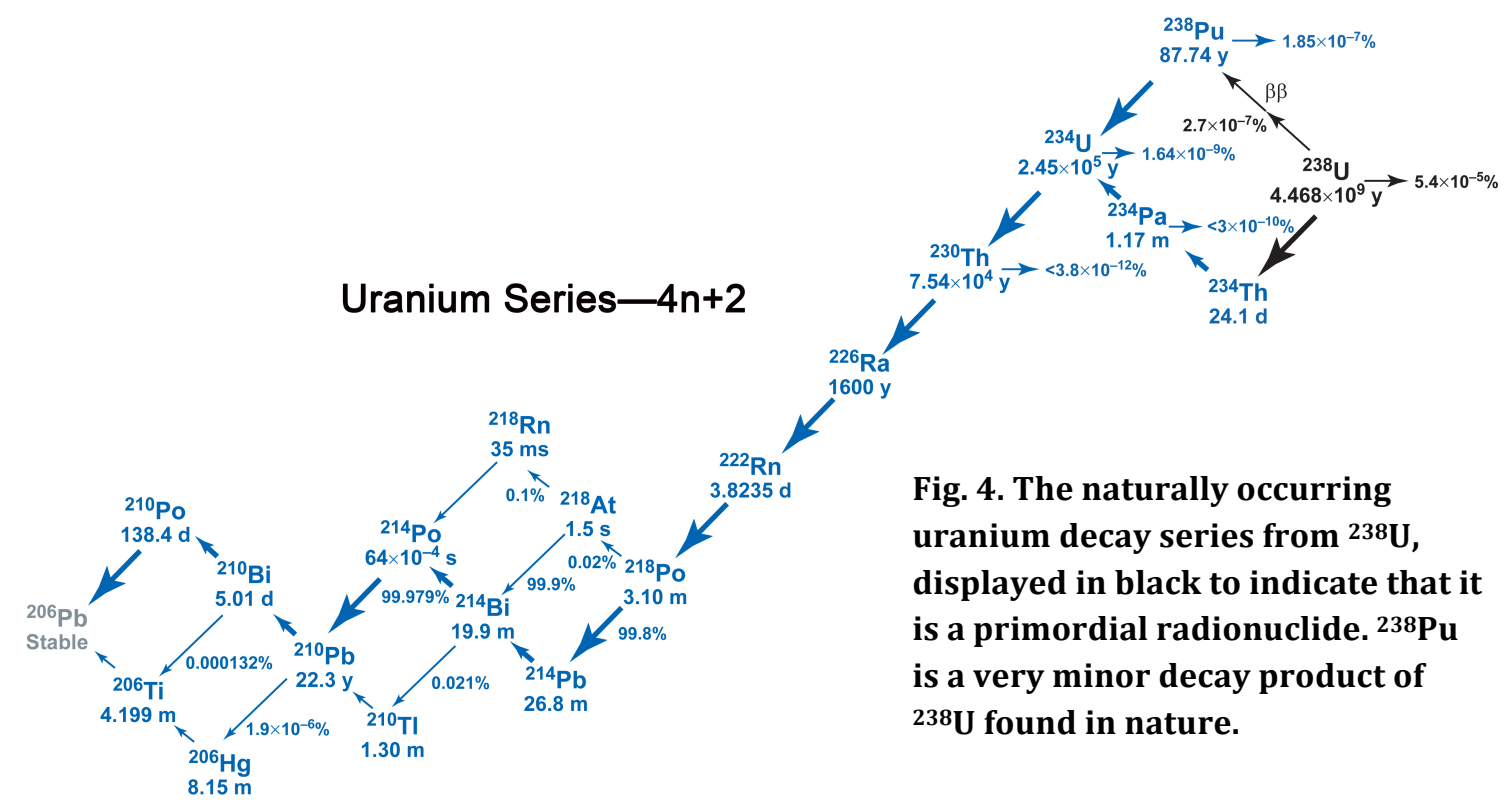

The figure illustrates that the intermediate nuclides in the series have short half-lives in comparison to uranium-2382. If a uranium-bearing system is left undisturbed for a few million years, a state of secular (long-term) equilibrium becomes established. In this case, the activities of all of the daughter nuclides are equal to the ${ }^{238} \mathrm{U}$ activities. However, during geological processes such as erosion, sedimentation, melting, or crystallization, different nuclides in the decay series can become fractionated relative to one another, due to variations in their chemistry or the structural site they occupy [28].

When making gamma-ray measurements in the field, we encounter natural uranium in two forms. The first is that gamma-ray field measurements, include some background radiation, in which ${ }^{238} \mathrm{U}$ and its daughter nuclides contribute significantly. Background radiation is ubiquitous, diffuse, and very low-level but can act as an interference with measurements of weak radioactive sources. The second natural uranium form, occasionally encountered in commerce, is uranium ore.

2 These short half-lives are useful for dating Pleistocene geological events that are too old to be well resolved by radiocarbon dating and too young to be well resolved by methods employing longer half-lives [28] 


\section{The thorium decay series}

Before we examine the gamma-ray spectra of background and uranium ore, we need to consider the other two sources besides the uranium series that contribute substantially to the structure of background spectra. The first of these is ${ }^{40} \mathrm{~K}$, a primordial radionuclide found in all potassium and is ubiquitous in the environment. A single 1460.8-keV gamma ray is emitted following the electron-capture decay of ${ }^{40} \mathrm{~K}$. The other major source of structure in background spectra is from the thorium decay series shown in Fig. 5. The figure also includes ${ }^{232} \mathrm{U}$, a man-made byproduct of plutonium production, and ${ }^{236} \mathrm{Pu}$, that are discussed in the following section on uranium enrichment.

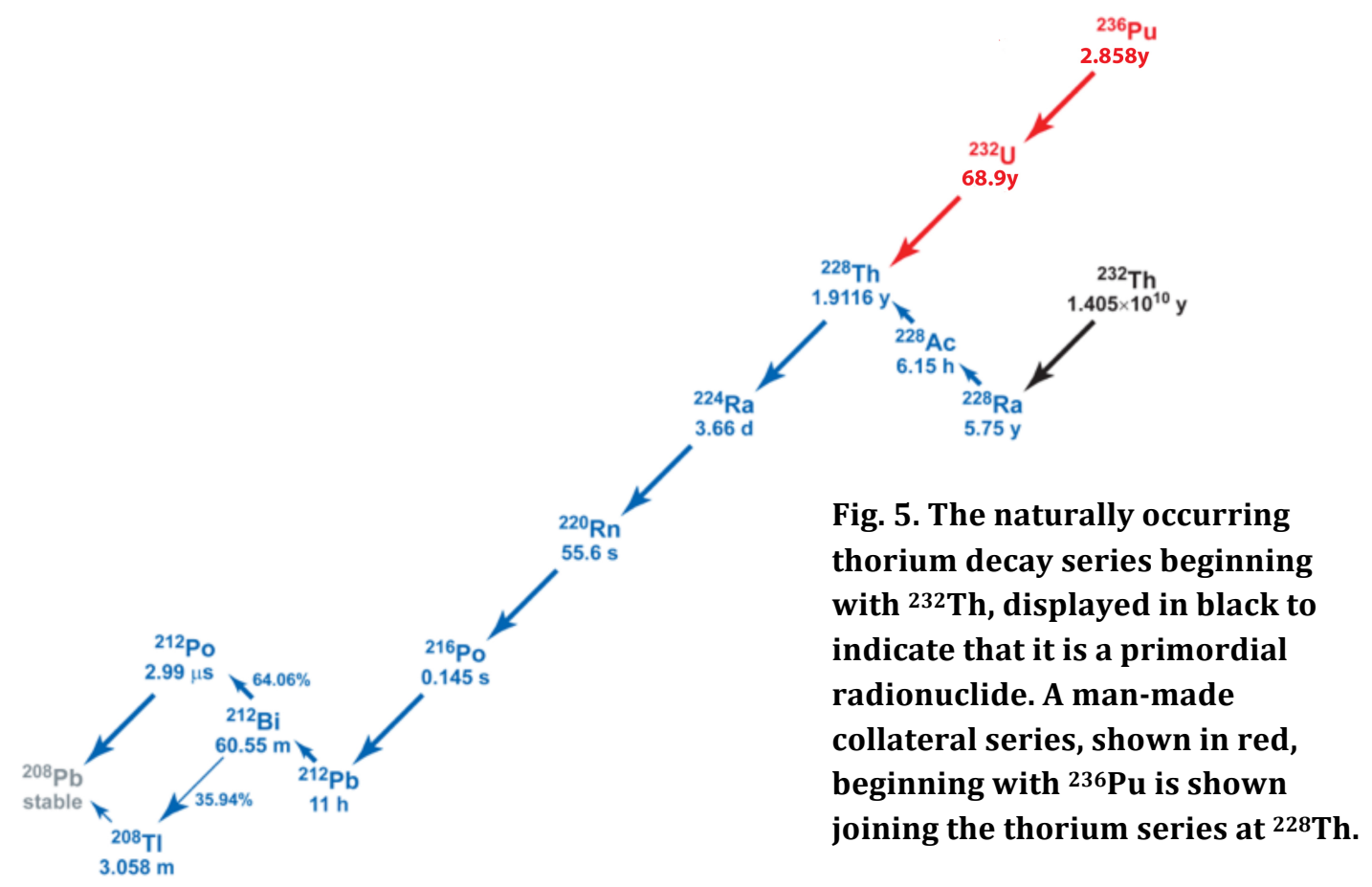

\section{Thorium-228: Nexus nuclide-a ubiquitous and ambiguous signature}

The natural thorium decay series arises from the decay of the $1.4 \times 10^{10}$-y primordial radionuclide ${ }^{232} \mathrm{Th}$. Thorium-228, with a 1.9-y half-life, is the great granddaughter of ${ }^{232} \mathrm{Th}$. It decays to seven successive radioactive daughters. These daughters are so short-lived that they require the presence of the longer-lived ${ }^{228} \mathrm{Th}$ to sustain their existence for more than a few weeks. One of these daughters, ${ }^{208} \mathrm{Tl}$, provides one of the most recognizable signatures in background radiation with strong gamma rays at 583-, 861-, and 2615-keV. Observation of ${ }^{208} \mathrm{Tl}$, therefore, almost always indicates the presence of ${ }^{228} \mathrm{Th}$. A computer-simulated point-source ${ }^{228} \mathrm{Tl}$ spectrum is shown in Fig. 6 illustrates the ${ }^{228} \mathrm{Th}$ signature.

The importance of ${ }^{228} \mathrm{Th}$ is that it is the nexus of two decay series with the nuclides, ${ }^{232} \mathrm{Th}$, ${ }^{232} \mathrm{U}$, and ${ }^{236} \mathrm{Pu}$ as their progenitors (Fig. 5). The presence of ${ }^{228} \mathrm{Th}$ in a gamma-ray spectrum is therefore not unique to a particular parent, which can make it a problematic but sometimes useful signature. Table 3 illustrates source types that produce ${ }^{228} \mathrm{Th}$ and their 
parents. The presence of ${ }^{208} \mathrm{Tl}$ and its significance in these source types is discussed separately.

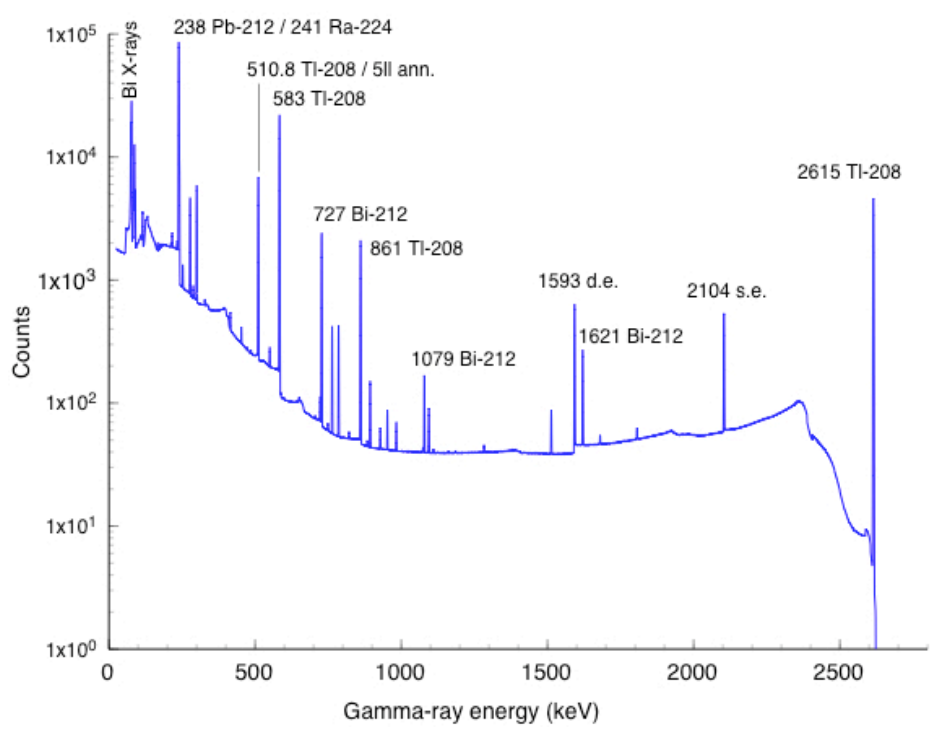

Fig. 6. Illustration of the ${ }^{228} \mathrm{Th}$ signature with a computer-simulated HPGe spectrum from a year-old ${ }^{228}$ Th point source

Table 3. Source types exhibiting a ${ }^{228} \mathrm{Th}$ signature

\begin{tabular}{ll}
\hline Source Type & ${ }^{228} \mathrm{Th}$ parent nuclide \\
\hline Background radiation & ${ }^{232} \mathrm{Th}$ \\
Gas lantern mantles & ${ }^{232} \mathrm{Th}$ \\
$\mathrm{HEU}$ and WGU & ${ }^{232} \mathrm{U}$ \\
${ }^{233} \mathrm{U}$ & ${ }^{232} \mathrm{U}$ \\
Heat-source $\mathrm{Pu}$ & ${ }^{236} \mathrm{Pu}$ \\
\hline Pu graded by ${ }^{240} \mathrm{Pu}$ content $[29]$ & \\
\hline Weapons-grade $\mathrm{Pu}\left(<7 \%{ }^{240} \mathrm{Pu}\right)$ & ${ }^{236} \mathrm{Pu}$ \\
Fuel-grade $\mathrm{Pu}\left(7 \% \geq{ }^{240} \mathrm{Pu}<19 \%\right)$ & ${ }^{236} \mathrm{Pu}$ \\
& \\
\hline
\end{tabular}

\section{Fluorine in uranium—Uranium hexafluoride and uranyl fluoride}

During uranium processing, milled uranium ore-or yellowcake (principally (triuranium octaoxide, $\left.\mathrm{U}_{3} \mathrm{O}_{8}\right)$-is chemically processed to produce uranium hexafluoride $\left(\mathrm{UF}_{6}\right)$. Uranium hexafluoride is used in both of the main uranium enrichment methods, gaseous diffusion and the gas centrifuge method. Uranyl fluoride $\left(\mathrm{UO}_{2} \mathrm{~F}_{2}\right)$ is an intermediate compound in the conversion of $\mathrm{UF}_{6}$ to a uranium oxide or metal form [30].

\footnotetext{
3 The use of thorium in lantern mantles has been discontinued in some countries.
} 
In both $\mathrm{UF}_{6}$ and $\mathrm{UO}_{2} \mathrm{~F}_{2}$, uranium, an alpha particle emitter, is in intimate contact with fluorine that is then subject to both ${ }^{19} \mathrm{~F}(\alpha, \mathrm{n}){ }^{22} \mathrm{Na}$ and ${ }^{19} \mathrm{~F}(\alpha, \mathrm{p})^{22} \mathrm{Ne}$ reactions. Both reactions populate the $1274.53-\mathrm{keV}$ excited state of ${ }^{22} \mathrm{Ne}$ that emits a gamma ray of that energy shown in Fig. 13. We do not currently have access to a spectrum of $\mathrm{UF}_{6}$ but it is reasonable to presume that a $1275 \mathrm{keV}$ peak would also be manifest in $\mathrm{UF}_{6}$.

The $1275 \mathrm{keV}$ gamma ray is the same gamma ray emitted by commonly used ${ }^{22} \mathrm{Na}$ calibration sources. However the common presence of uranium in a spectrum and a 1275 $\mathrm{keV}$ gamma ray is a likely signature for uranium in the midst of processing.

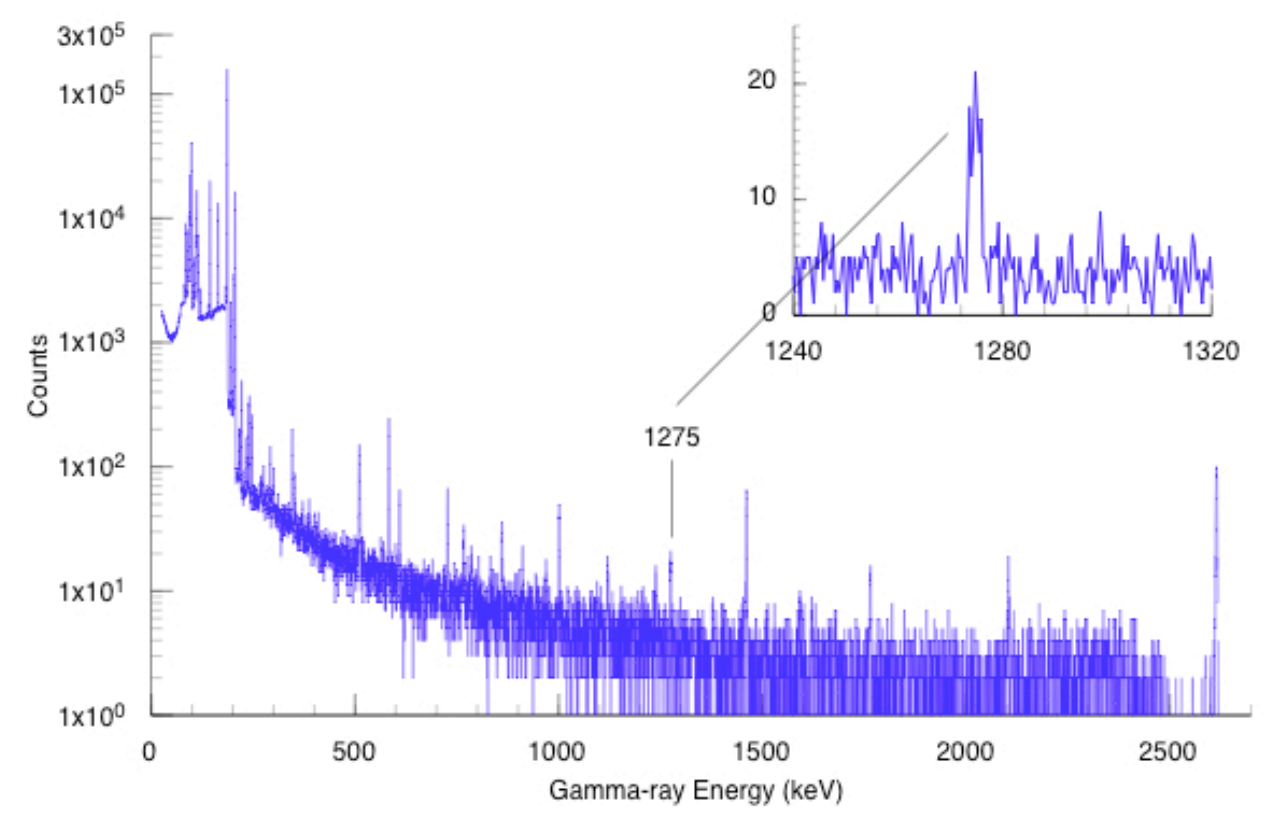

Fig. 13. Gamma-ray spectrum of enriched uranium residue, including uranyl fluoride, showing the $1275-\mathrm{keV}$ peak emitted following alpha-particle activation of ${ }^{19} \mathrm{~F}$.

\section{The uranium contribution to background spectra}

The HPGe background spectrum in Fig. 7 was accumulated for nearly 18 days to reveal many of the background peaks that are not observed in shorter counting intervals 4 . The uranium ore spectrum in Fig. 7 was accumulated for 564 s live time. To isolate and emphasize the structure of the ore spectrum, we present it as a "net" spectrum; a reliable background spectrum was taken immediately after the foreground spectrum and subtracted on a channel-by-channel basis. In this spectrum there are 50 or more manifest peaks. The majority of the peaks are from decay of the distant ${ }^{238} \mathrm{U}$ daughter ${ }^{214} \mathrm{Bi}$. Next in number are photopeaks from ${ }^{214} \mathrm{~Pb}$ and a single peak from ${ }^{226} \mathrm{Ra}$ at $186.2-\mathrm{keV}$. Save for the ${ }^{226} \mathrm{Ra}$ peak itself, all of these are ${ }^{226} \mathrm{Ra}$ daughters. Were it not for the presence of the ${ }^{234 \mathrm{mPa}}$

4 Many more background peaks can be observed if background data are accumulated for a considerably extended period of time. See [31] for a spectrum accumulated from 0-1540-keV for $1.03 \times 10^{8} \mathrm{~s}(\sim 3.3 \mathrm{y})$. 
1001-keV peak, they would represent a spectrum of pure ${ }^{226 \mathrm{Ra}}$ such as used medically for brachytherapy and, in the past, on radioluminescent watch and instrument dials [31]. Comparing the background spectrum to the net uranium ore spectrum, we see the ${ }^{40} \mathrm{~K}$ peak at $1461-\mathrm{keV},{ }^{214} \mathrm{~Pb}$ peaks, and peaks from nuclides in the thorium series, notably ${ }^{228} \mathrm{Ac}$ and $208 \mathrm{Tl}$.

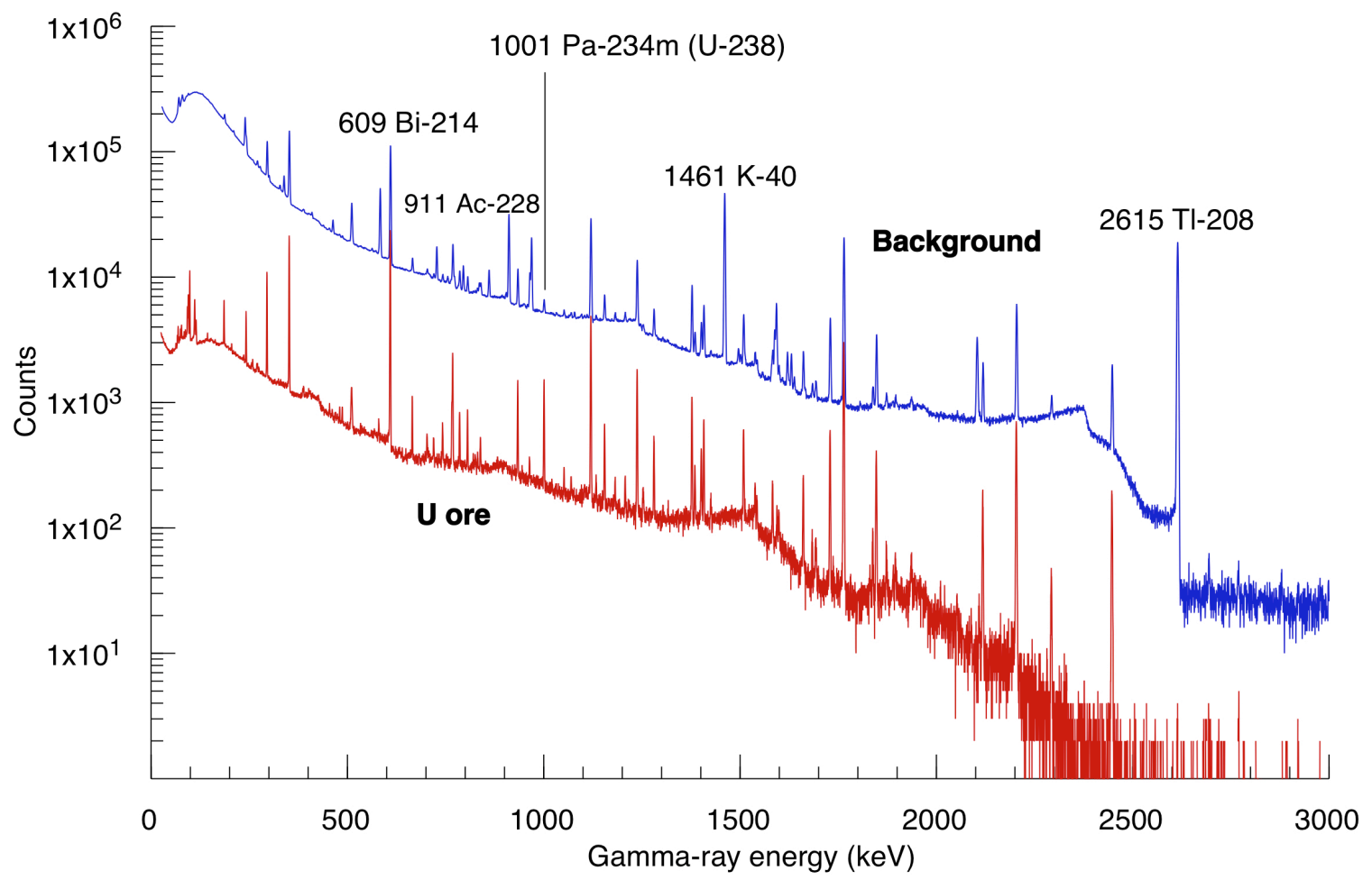

Fig. 7. Gamma-ray pulse-height spectra of background and uranium ore taken with HPGe detectors of $20 \%$ nominal relative efficiency [33]. The background spectrum was accumulated for $1.532 \times 10^{6} \mathrm{~s}$, or about 18 days. The ore spectrum was accumulated for $564 \mathrm{~s}$ live time at $100 \mathrm{~cm}$ with $13 \%$ dead time. A background spectrum, taken after the foreground spectrum, was subtracted to produce a net ore spectrum. The same natural uranium peaks appear in the background spectrum where the contributions from ${ }^{40} \mathrm{~K}$ and ${ }^{232} \mathrm{Th}$ decay are also apparent. Some of the most prominent background peaks are called out for subsequent discussion.

Because of its strong presence in background, in some circumstances background uranium radiation could largely mask the presence of a uranium ore signature. However, because uranium is usually a diffuse trace element in the earth's crust, internal conversion following alpha decays of the uranium isotopes results in thorium $\mathrm{K} \mathrm{X}$-ray emissions that are usually too weak in background to be reliably observed. In the case of uranium ore, however, the density of uranium atoms is considerable and the decay products of the alpha decays stimulate uranium K-series fluorescence in nearby uranium atoms. This appears in the 95$115 \mathrm{keV}$ region. The strongest of these is the $K_{\alpha_{1}} \mathrm{X}$-ray at $98.44 \mathrm{keV}$ and the $K_{\beta_{1}}^{\prime}\left(K_{\beta_{1}}+K_{\beta_{3}}+K_{\beta_{5}}\right)$ peak at $111 \mathrm{keV}$ that are an observable tell for the presence of lightly or unshielded uranium ore. This X-ray signature is visible in Fig. 7 and more clearly in an expanded view of the low-energy region in Fig. 8. 


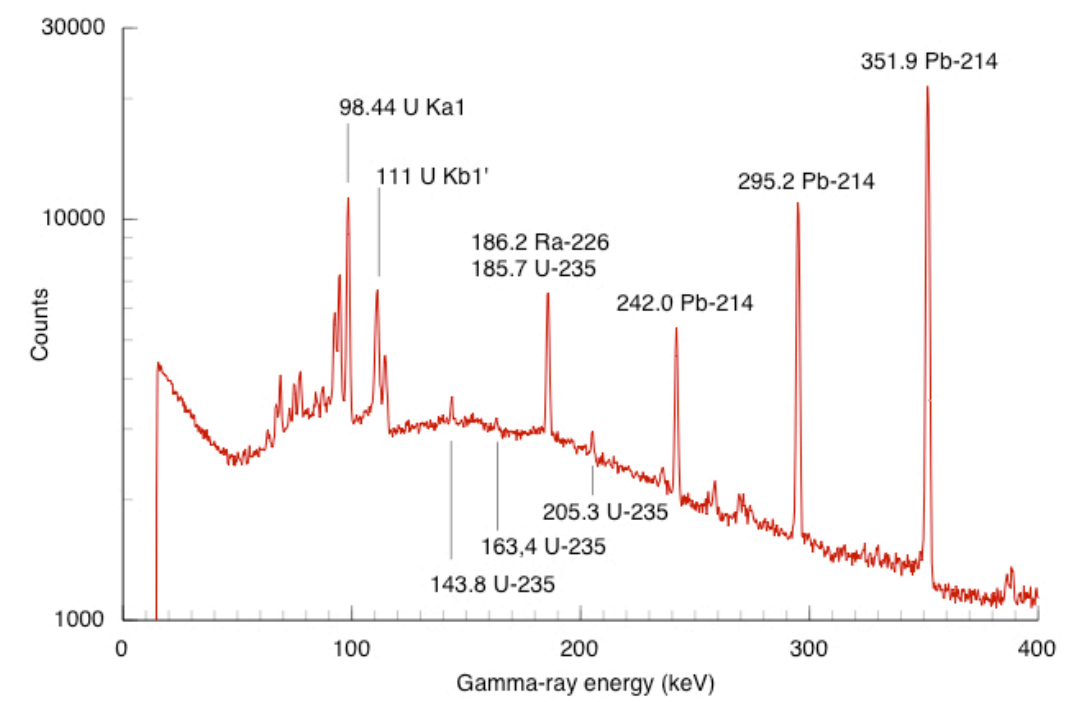

Fig. 8. An expanded view of the high-resolution gamma-ray spectrum from uranium ore from Fig. 7 showing the four-peak ${ }^{226}$ Ra signature. The first of the four peaks is an unresolved doublet with an average energy at around 186-keV, formed by the $186.2-\mathrm{keV}$ peak from ${ }^{226} \mathrm{Ra}$ and the $185.7-\mathrm{keV}^{235} \mathrm{U}$ peak from the Actinium decay series. The other three peaks are from the ${ }^{214} \mathrm{~Pb}$ daughters of ${ }^{226} \mathrm{Ra}$.

The uranium ore spectrum in Fig. 8 has excellent counting statistics and, to the experienced eye of a gamma-ray spectrometrist, there actually is direct evidence of the presence of ${ }^{235} \mathrm{U}$. Weak 235U peaks are observable at 143- and 205-keV. Midway between the 143- and 185$\mathrm{keV}$ peaks there is a "nubbin" that is an incipient $163-\mathrm{keV}{ }^{35} \mathrm{U}$ peak. The HPGe ID did not find the Poisson signal-to-noise ratios for the 163 - and $205-\mathrm{keV}$ peaks to exceed the detection thresholds. The signal-to-noise ratio for the $143 \mathrm{keV}$ peak was just high enough for HPGe ID to exceed its signal-to-noise $(\mathrm{S} / \mathrm{N})$ threshold of marginality $(4<\mathrm{S} / \mathrm{N} \leq 5)$ but not to be declared manifest $(\mathrm{S} / \mathrm{N}>5)$.

\section{More observations about background interference in field measurements}

Background radiation is ever present in field spectra and can interfere with the signal of interest from a measured radiation source. If the signal of interest is especially weak, background can even mask the source presence entirely. To mitigate this difficulty, in typical radioanalytical laboratory measurements, samples are prepared by a radiochemist in a standard geometry and counted in a standard geometry in a heavily shielded counting chamber in a laboratory. This dramatically reduces background intensity and diurnal background variation in the chamber and allows for an accurate background measurement when the source is absent.

In contrast, it is extremely difficult to measure a trustworthy background spectrum in the field. Moving or reorienting the detector to obtain a source-free background measurement will frequently produce a measurement that will likely differ significantly, and sometimes even exceeding, the true background at the source position. It is not at all unusual for environmental background to vary significantly over distances of a few meters. As a result, we typically confine our analyses to the foreground spectrum, as generally reflected in the remainder of this paper, although a circumstance that requires background consideration is noted in the following section on uranium enrichment. 


\section{Detecting the presence of uranium}

\section{Key full-energy peaks from uranium isotopes and collateral nuclides}

There are many isotopes of uranium. In this section we discuss those that occur in nature or are the result of reprocessing uranium. The radiation signatures of uranium vary from its natural states to its many processed forms. While there are hundreds of gamma rays emitted by these nuclides and their decay daughters, the vast majority of these emissions are too weak to be reliably observed with field measurements of typically short duration. For rapid identification of uranium from sparse gamma-ray spectra, of necessity, we need to be concerned with the most intense gamma rays associated with their decay. These are shown in Table 4 with their energies and emission intensities in percent, $I \gamma(\%)$, along with others that are mentioned in this paper.

Table 4. Key peaks and emission intensities from uranium isotopes and collateral nuclides [34]

\begin{tabular}{|c|c|c|c|c|c|c|c|}
\hline Nuclide & Daughters & Energy (keV) & $\mathbf{I} \gamma(\%)$ & Nuclide & Daughters & Energy (keV) & $\mathbf{I} \gamma(\%)$ \\
\hline \multirow[t]{2}{*}{$\mathrm{U}$} & U Ka1 X-ray & 98.44 & (100 rel.) & \multirow[t]{3}{*}{${ }^{19} \mathrm{~F}$} & & Stable no $\mathbf{g}$ & \\
\hline & U Kb1' X-ray & 111. & (38 rel.) & & ${ }^{19} \mathrm{~F}(\mathrm{a}, \mathrm{n}){ }^{22} \mathrm{Na}$ & 1274.53 & \\
\hline \multirow[t]{6}{*}{${ }^{232} \mathrm{U}$} & \multirow{6}{*}{${ }^{208} \mathrm{Tl}$} & 57.77 & 0.1999 & & ${ }^{19} \mathrm{~F}(\mathrm{a}, \mathrm{p}){ }^{22} \mathrm{Ne}$ & 1274.53 & \\
\hline & & 129.06 & 0.0682 & \multirow[t]{2}{*}{$\mathrm{Pb}$} & Pb Ka1 X-ray & 74.97 & (100 rel.) \\
\hline & & 270.24 & 0.00316 & & $\mathrm{~Pb} \mathrm{Ka} 2^{\prime}$ X-ray & 84.8 & (35 rel.) \\
\hline & & 328.00 & 0.00283 & \multirow[t]{2}{*}{${ }^{214} \mathrm{Bi}$} & & 609.31 & 46.1 \\
\hline & & 583.19 & 84.5 & & & 768.36 & 4.94 \\
\hline & & 2614.53 & 99. & \multirow[t]{4}{*}{${ }^{226} \mathrm{Ra}$} & \multirow{4}{*}{${ }^{214} \mathrm{~Pb}$} & 186.21 & 3.59 \\
\hline \multirow[t]{3}{*}{${ }^{233} \mathrm{U}$} & & 317.16 & 0.00776 & & & 242.00 & 7.43 \\
\hline & & 320.54 & 0.00290 & & & 295.22 & 19.3 \\
\hline & & 323.42 & 0.00077 & & & 351.93 & 37.6 \\
\hline${ }^{234} \mathrm{U}$ & & 120.9 & 0.0342 & \multirow[t]{5}{*}{${ }^{2337} \mathrm{~Np}$} & Np Ka1 X-ray & 101.07 & (100 rel.) \\
\hline \multirow[t]{4}{*}{${ }^{235} \mathrm{U}$} & & 143.76 & 10.96 & & Np Kb1' X-ray & 104. & (39 rel.) \\
\hline & & 163.36 & 5.08 & & ${ }^{233} \mathrm{~Pa}$ & 300.34 & 6.62 \\
\hline & & 185.70 & 57.2 & & & 312.17 & 38.6 \\
\hline & & 205.31 & 5.01 & & & 340.81 & 4.47 \\
\hline \multirow[t]{11}{*}{${ }^{238} \mathrm{U}$} & \multirow{3}{*}{${ }^{234 \mathrm{~m}} \mathrm{~Pa}$} & Various & Weak & ${ }^{228} \mathrm{Ac}$ & & 911.20 & 25.8 \\
\hline & & 766.38 & 0.294 & \multirow[t]{6}{*}{${ }^{228} \mathrm{Th}$} & & Few & Weak \\
\hline & & 1001.03 & 0.837 & & ${ }^{208} \mathrm{Tl}$ & 583.19 & 84.5 \\
\hline & ${ }^{226} \mathrm{Ra}$ & 186.21 & 3.59 & & & 2614.53 & 99. \\
\hline & ${ }^{214} \mathrm{~Pb}$ & 242.00 & 7.43 & & ${ }^{212} \mathrm{~Pb}$ & 238.63 & 43.3 \\
\hline & & 295.22 & 19.3 & & Bi Ka1 X-ray & 77.11 & (100 rel.) \\
\hline & & 351.87 & 37.6 & & Bi Ka2’ X-ray & 87.2 & (36 rel.) \\
\hline & \multirow[t]{4}{*}{${ }^{214} \mathrm{Bi}$} & 609.31 & 46.1 & \multirow[t]{2}{*}{${ }^{238} \mathrm{Pu}$} & & 766.38 & 0.000022 \\
\hline & & 768.36 & 4.94 & & & 1001.03 & 0.0000010 \\
\hline & & & & \multirow[t]{2}{*}{${ }^{239} \mathrm{Pu}$} & & 375.04 & 0.001554 \\
\hline & & & & & & 413.71 & 0.001416 \\
\hline
\end{tabular}




\section{Uranium-235-The only fissile primordial nuclide:}

Uranium-235 is a radioisotope of uranium making up $0.755 \%$ of natural uranium by weight with a half-life of 704 million years. It is the progenitor of another decay series, the actinium series, whose daughters typically do not produce manifest gamma-ray emissions in field measurements. It is also the only fissile isotope that is a primordial nuclide or found in significant quantity in nature. Uranium-235 is of great importance as the primary energy source used in most nuclear power reactors and because domestic and international safeguards recognize that uranium enriched to $\geq 20 \%$ of ${ }^{235} \mathrm{U}$ by weight (highly enriched uranium, $\mathrm{HEU}$ ) can be used to build nuclear weapons [35].

Uranium-235 does not usually display a usable gamma-ray signature in background radiation because it is masked by ${ }^{226} \mathrm{Ra}$. The distinguishing radiation signature of ${ }^{226} \mathrm{Ra}$ is the picket-fence-like structure of four peaks ranging from 186- to $352-\mathrm{keV}$ shown in the uranium ore spectrum shown in Fig. 8. From Table 4 we see that the most intense gamma ray from $235 \mathrm{U}$ occurs at $185.70-\mathrm{keV}$ and the next most while ${ }^{226} \mathrm{Ra}$ emits a gamma ray at 186.21-keV. "These peaks are so close together that deconvolution in real environmental spectra is unlikely to give results that one can have confidence in [36]." Unshielded or lightly shielded processed ${ }^{235} \mathrm{U}$ is easily detected by the presence of the four ${ }^{235} \mathrm{U}$ low-energy gamma rays at 143-, 163-, 186-, and $205-\mathrm{keV}$ and the absence of strong peaks from ${ }^{214} \mathrm{~Pb}$ as shown in Fig. 8.

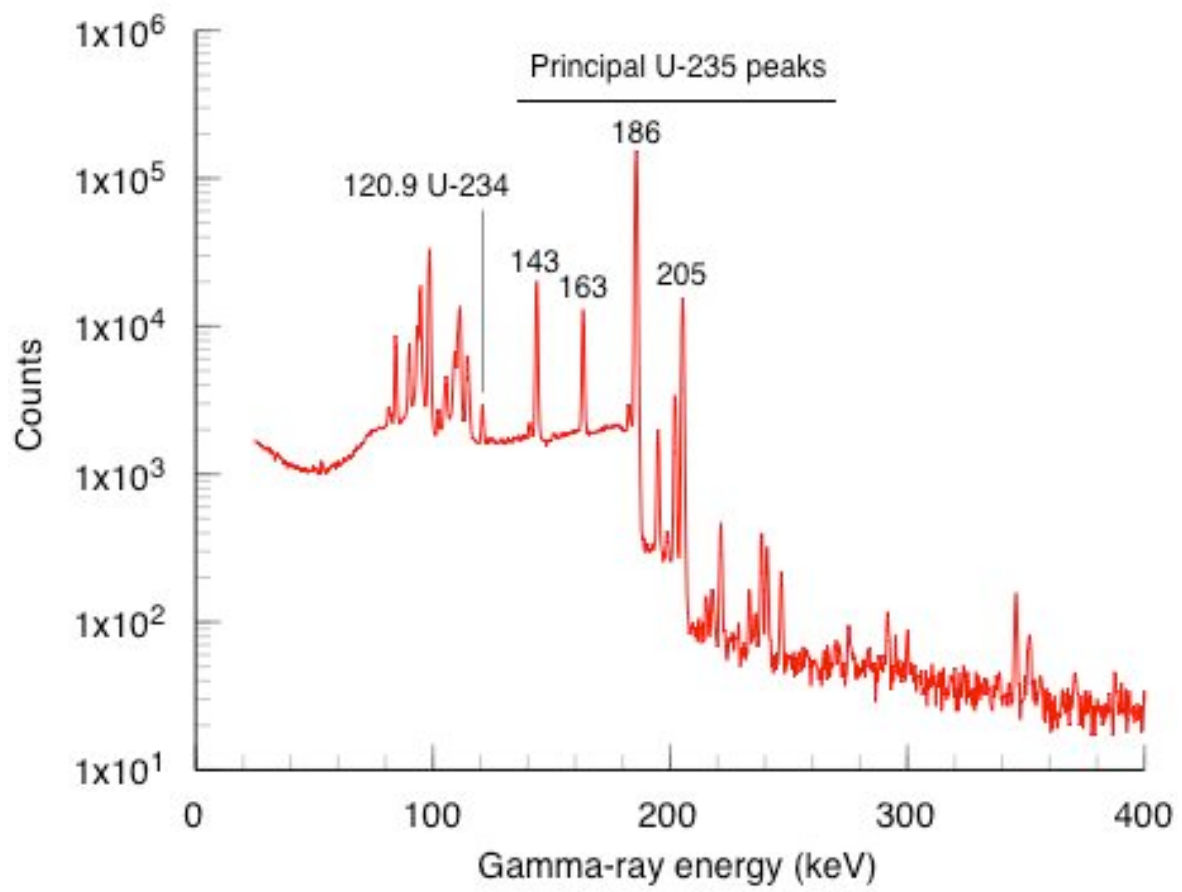

Fig. 9. Low-energy portion of a gamma-ray spectrum of uranium, enriched to $93 \%{ }^{235} \mathrm{U}$, showing the key peaks used for identification of the presence of ${ }^{235} \mathrm{U}$ and the $120.90-\mathrm{keV}$ peak from ${ }^{234} \mathrm{U}$ decay. 
Masking ${ }^{235} \mathrm{U}$

If the four characteristic ${ }^{235} \mathrm{U}$ gamma peaks are manifest, we can have high confidence in the identification of ${ }^{235} \mathrm{U}$. However, weak emissions, shielding, or downscatter from higher energy peaks can obscure the peaks at 143-, 163-, and 205-keV, such that only the 185.7-keV peak remains manifest. Several radionuclides of interest in HPGe ID have strong gamma lines near $185.7-\mathrm{keV}$ and can mask the presence of HEU in situations where the ${ }^{238} \mathrm{U}$ signature is too weak to be manifest as well. These nuclides are medical ${ }^{67} \mathrm{Cu}(184.58-\mathrm{keV})$, medical ${ }^{67} \mathrm{Ga}(184.58-\mathrm{keV}$, same gamma ray as $\left.{ }^{67} \mathrm{Cu}\right)$, check source ${ }^{166 \mathrm{~m}} \mathrm{Ho}(184.41-\mathrm{keV})$, and naturally occurring ${ }^{226} \mathrm{Ra}$ (186.21). The HPGe ID rules include a section that steps through each of these nuclides and provides methods that undertake detecting such masking.

\section{Uranium-238-A fertile primordial nuclide:}

Uranium-238 is the most common naturally occurring uranium isotope, making up $99.274 \%$ of natural uranium by weight with a half-life of 4.468 billion years. It is not fissile but is a fertile material: it can capture a slow neutron and after two beta decays become fissile ${ }^{239} \mathrm{Pu}$. Uranium-238 is fissionable by fast neutrons, but cannot support a chain reaction. The distant daughters of ${ }^{238} \mathrm{U}$, particularly ${ }^{226} \mathrm{Ra},{ }^{214} \mathrm{~Pb}$, and ${ }^{214} \mathrm{Bi}$ account for a majority of the peaks manifest in the spectrum of uranium ore.

We see from Table 4 that direct radiations from long-lived ${ }^{238} \mathrm{U}$ are too weak or too low in energy to be useful for field measurements. This is also true of its daughter ${ }^{234} \mathrm{Th}$. From Fig. 4 we observe that ${ }^{234}$ Th has a half-life of 24.1 days. Within five ${ }^{234}$ Th half-lives, or less than 5 months, secular equilibrium of ${ }^{234} \mathrm{Th}$ will be within a few percent of establishment. $234 \mathrm{mPa}$ with its half-life of $1.17 \mathrm{~m}$ will have been in equilibrium with ${ }^{234} \mathrm{Th}$ in minutes. Thorium-234 in turn largely decays to the metastable state of its daughter $234 \mathrm{mPa}$ that then largely beta decays directly to excited states of ${ }^{234} \mathrm{U}$. These states emit highly penetrating gamma-ray emissions at 766.41 - and $1001.03-\mathrm{keV}$. The presence of $238 \mathrm{U}$ can be initially inferred from the presence of these two gamma rays.

\section{Identification of ${ }^{238} \mathrm{U}$ in natural uranium}

In natural uranium it is tempting to simply identify the presence of ${ }^{238} \mathrm{U}$ solely from the 766.41 and $1001.03-\mathrm{keV}$ peaks, however there is interference from an unresolved ${ }^{214} \mathrm{Bi}$ peak from natural uranium at 768.38-keV (Fig.10). We found that, for detection of 238U, integrating the doublet, rather than resolving it, is desirable and the motivation for doing this is discussed in the final section of this paper. Furthermore, the presence of uranium ore, identified from the presence of manifest ${ }^{226} \mathrm{Ra}$, and the $1001.03-\mathrm{keV} 234 \mathrm{mPa}$ gamma ray indicate that $238 \mathrm{U}$ is present. In chemically processed uranium, the processing removes the ${ }^{238} \mathrm{U}$ daughters, except for ${ }^{234} \mathrm{U}$ and ingrowth of ${ }^{226} \mathrm{Ra}$ and its ${ }^{214} \mathrm{Bi}$ daughter gamma ray at $768.36-\mathrm{keV}$ is too slow to be competitive with the ${ }^{238 \mathrm{U}} 766.41-\mathrm{keV}$ peak in a human lifetime. So tentative identification of $238 \mathrm{U}$ is possible with the presence of the 766.38 and $1001.03-$ $\mathrm{keV}$ gamma rays. Their presence is necessary but not sufficient to avoid misidentification as ${ }^{238} \mathrm{Pu}$. 


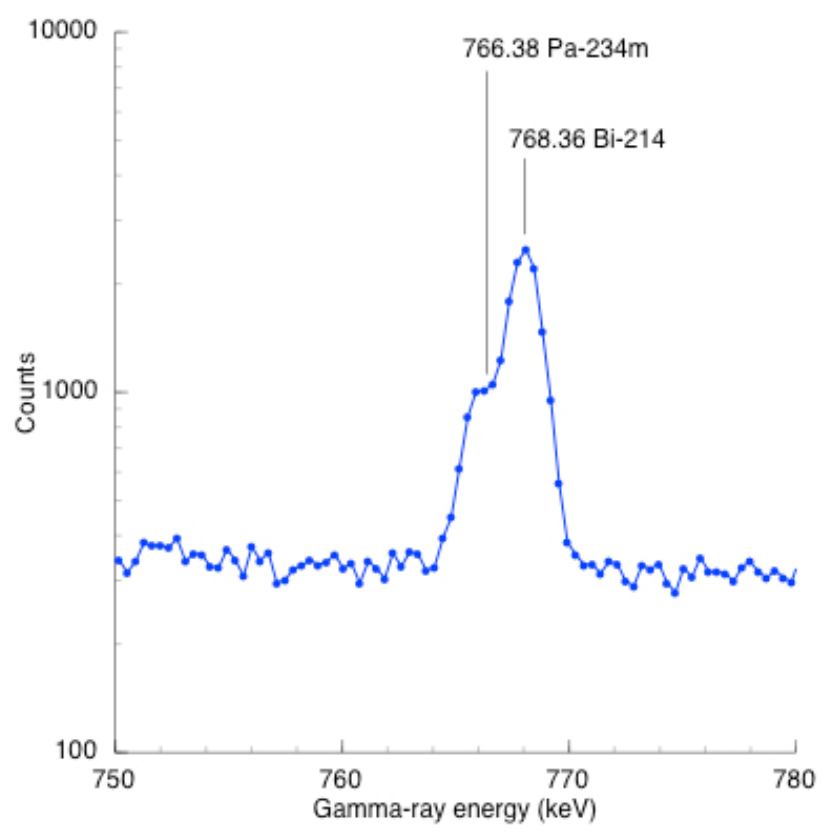

Fig. 10. The doublet formed by the 766.41 $234 \mathrm{mPa}$ peak and the 768.36keV peak from ${ }^{214} \mathrm{Bi}$ in the uranium ore spectrum shown in Fig. 7.

\section{Uranium-234-Naturally occurring, not primordial-another decay series nexus}

Uranium-234 is naturally occurring but not primordial because its half-life is only 245,500 years. Its existence is the result of the decay of primordial $238 \mathrm{U}$ and is its greatgranddaughter. It makes up only $0.0055 \%$ of natural uranium. The importance of ${ }^{234} \mathrm{U}$ for uranium identification is that its excited states yield the dominant gamma rays that indicate the presence of $238 \mathrm{U}$. These same gamma rays, but with extremely low emission intensities and different relative intensities, are also the dominant signature of substantial quantities of $238 \mathrm{Pu}$.

Enriched uranium contains more ${ }^{234} \mathrm{U}$ than natural uranium as a byproduct of the uranium enrichment that concentrates lighter isotopes even more strongly than it does 235U [37]. While ${ }^{234} \mathrm{U}$ is not fissile it is fertile and absorbs slow neutrons in a nuclear reactor to become fissile $235 \mathrm{U}$. This may be undesirable in some reactors as it changes the reactivity of the uranium [26].

The presence of ${ }^{234} \mathrm{U}$ in the gamma-ray spectrum of HEU can be observed although its gamma-ray emissions are quite weak. The two strongest are $53.20-\mathrm{keV}$ at $0.123 \%$ emission intensity and $120.90-\mathrm{keV}$ at $0.0342 \%$. The low-energy region of the gamma-ray spectrum of WGU is shown in Fig. 9. The detector efficiency is degraded at 53-keV but an apparent tiny visible peak at about $53-\mathrm{keV}$ might be from ${ }^{234} \mathrm{U}$. The detector is far more efficient at $121-\mathrm{keV}$ and a small peak is manifest between the "forest" of low-energy gamma rays and U K-series X-rays below about $115-\mathrm{keV}$ and the $143-\mathrm{keV} 235 \mathrm{U}$ gamma ray. 


\section{Uranium-232-Possible HEU signature, parasitic impurity}

With only a 69-year half-life, ${ }^{232} \mathrm{U}$ does not occur in nature but is introduced as a result of reactor irradiation of uranium. In the 1960's, uranium that had previously been irradiated in reactors was introduced into U.S. gaseous diffusion plants to be re-enriched. Consequently, trace quantities of $232 \mathrm{U}$ were entrained in the gaseous diffusion cascades where they remain today and became a minor contaminant in new feedstock as it was introduced to the cascade. During enrichment it is preferentially swept into the light isotope fraction that becomes HEU. Its presence as a possible indicator of shielded HEU is discussed in a following section.

Uranium-232 is found in reprocessed uranium. During its irradiation in a reactor, uranium is profoundly modified. It contains all the isotopes of uranium between ${ }^{232} \mathrm{U}$ and ${ }^{238} \mathrm{U}$ except ${ }^{237} \mathrm{U}$, which is rapidly transformed into ${ }^{237} \mathrm{~Np}$.

Uranium-232 is also a parasitic impurity formed in the production of fissile ${ }^{233} \mathrm{U}$. Its importance is discussed in the following description of $233 \mathrm{U}$.

\section{Uranium-233-Looking to the future and the thorium fuel cycle}

Uranium-233 is a fissile uranium isotope with a half-life of 159.2 thousand years that does not occur in the earth's crust. It is bred from ${ }^{232} \mathrm{Th}$ to become part of a thorium fuel cycle. Because ${ }^{233} \mathrm{U}$ is fissile, there have been concerns that it could be used in nuclear weapons. ${ }^{233} \mathrm{U}$ has also been considered as a reactor fuel but was never used commercially for this purpose. This is because the intense gamma radiation from the decay daughters of parasitic ${ }^{232} \mathrm{U}$, a byproduct of ${ }^{233} \mathrm{U}$ production, makes the ${ }^{233} \mathrm{U}$ hazardous to handle.

Production of ${ }^{233} \mathrm{U}$ via neutron irradiation of $232 \mathrm{Th}$ produces small amounts of ${ }^{232} \mathrm{U}$ as an impurity, because of $(n, 2 n)$ reactions on ${ }^{233} \mathrm{U}$ itself, or on ${ }^{233} \mathrm{~Pa}[38,39]$ :

$$
\begin{aligned}
& { }^{232} \mathrm{Th}(\mathrm{n}, \gamma){ }^{233} \mathrm{Th}\left(\beta^{-}\right){ }^{233} \mathrm{~Pa}\left(\beta^{-}\right){ }^{233} \mathrm{U}(\mathrm{n}, 2 \mathrm{n}){ }^{232} \mathrm{U} \\
& { }^{232} \mathrm{Th}(\mathrm{n}, \gamma){ }^{233} \mathrm{Th}\left(\beta^{-}\right){ }^{233} \mathrm{~Pa}(\mathrm{n}, 2 \mathrm{n}){ }^{232} \mathrm{~Pa}\left(\beta^{-}\right){ }^{232} \mathrm{U} \\
& { }^{232} \mathrm{Th}(\mathrm{n}, 2 \mathrm{n}){ }^{231} \mathrm{Th}\left(\beta^{-}\right){ }^{231} \mathrm{~Pa}(\mathrm{n}, \gamma){ }^{232} \mathrm{~Pa}\left(\beta^{-}\right){ }^{232} \mathrm{U}
\end{aligned}
$$

The decay products of parasitic ${ }^{232} \mathrm{U}$ enter the thorium decay series and, because of its high specific activity relative to other present uranium isotopes, quickly yields a strong ${ }^{228} \mathrm{Th}$ signature. For this reason ${ }^{232} \mathrm{U}$ has been cited as an obstacle to nuclear proliferation by using ${ }^{233} \mathrm{U}$ as the fissile material [40]. This is because it makes manual spent fuel handling in a glove box with only light shielding (as commonly done with plutonium) too hazardous, (except possibly in a short period immediately following chemical purification of the uranium). Instead it will require using costly remote manipulation.

Nevertheless, international interest in thorium energy has renewed [41]. Moreover, for over 50 years India has invested in the long-term development of a thorium fuel cycle. India's vast population and widespread poverty places it in great need of increased energy production to improve quality of life. India's coal and uranium reserves are limited. However, India's reserve in thorium is estimated at 300,000 metric tons. With the country's great need for energy and its vast thorium reserves, in the 1950's Indian physicist Homi 
Jehangir Bhabha proposed a three-stage program to bootstrap its limited nuclear resources into a viable thorium-based nuclear energy program [42]. This thorium fuel cycle is expected to lead to the use of thorium-based reactors to meet $30 \%$ of its electricity demands by 2050 [43]. The Indian plan has entered its third stage and a thorium fuel cycle Advanced Heavy Water Reactor (AHWR) with mixed oxide fuel (Th-LEU) is planned for operation before the end of this decade.

Anticipating the possible future appearance of illicit 233U "in the wild," it is prudent to examine its likely gamma-ray signature. With a uranium isotopic vector at reactor discharge, we can model its likely gamma-ray spectrum and study the effect of ${ }^{228} \mathrm{Th}$ ingrowth on the spectral structure as a function of time. This structure will depend on the nature of the reactor fuel and its burnup. We can use the projected AHWR uranium isotopic input and output vectors [44], shown in Table 5, to illustrate the rapidity of 228Th ingrowth.

Table 5. Uranium isotopic vectors for initial and discharged AWHR fuel

\begin{tabular}{lccccccc}
\hline Fuel burnup & ${ }^{232} \mathbf{U} \%$ & ${ }^{233} \mathbf{U} \%$ & ${ }^{234} \mathbf{U} \%$ & ${ }^{235} \mathbf{U} \%$ & ${ }^{236} \mathbf{U} \%$ & ${ }^{237} \mathbf{U} \%$ & ${ }^{238} \mathbf{U} \%$ \\
\hline Initial & 0.0 & 0.0 & 0.0 & 19.75 & 0.0 & 0.0 & 80.25 \\
\hline $\begin{array}{l}\text { Discharge } \\
(64 \text { GWd/Te) }\end{array}$ & 0.02 & 6.51 & 1.24 & 1.62 & 3.26 & 0.00 & 87.35 \\
\hline
\end{tabular}

We modeled expected spectra from a 20\% HPGe detector, as a function of time following discharge, for 1000-s counts at 1-meter from a 5-kg sphere, formed from this output vector. This is shown in Fig. 11.

After 1-day, the ${ }^{228} \mathrm{Th}$ signature is already strongly present but structure from other nuclides, including direct decay gamma rays from ${ }^{232} \mathrm{U}$ and ${ }^{233} \mathrm{U}$ below $400 \mathrm{keV}$, is also manifest. After 1-week, the ${ }^{228} \mathrm{Th}$ structure is largely dominant. After 1 month and certainly 1-year, the ${ }^{228} \mathrm{Th}$ structure almost completely masks the presence of other nuclides. 


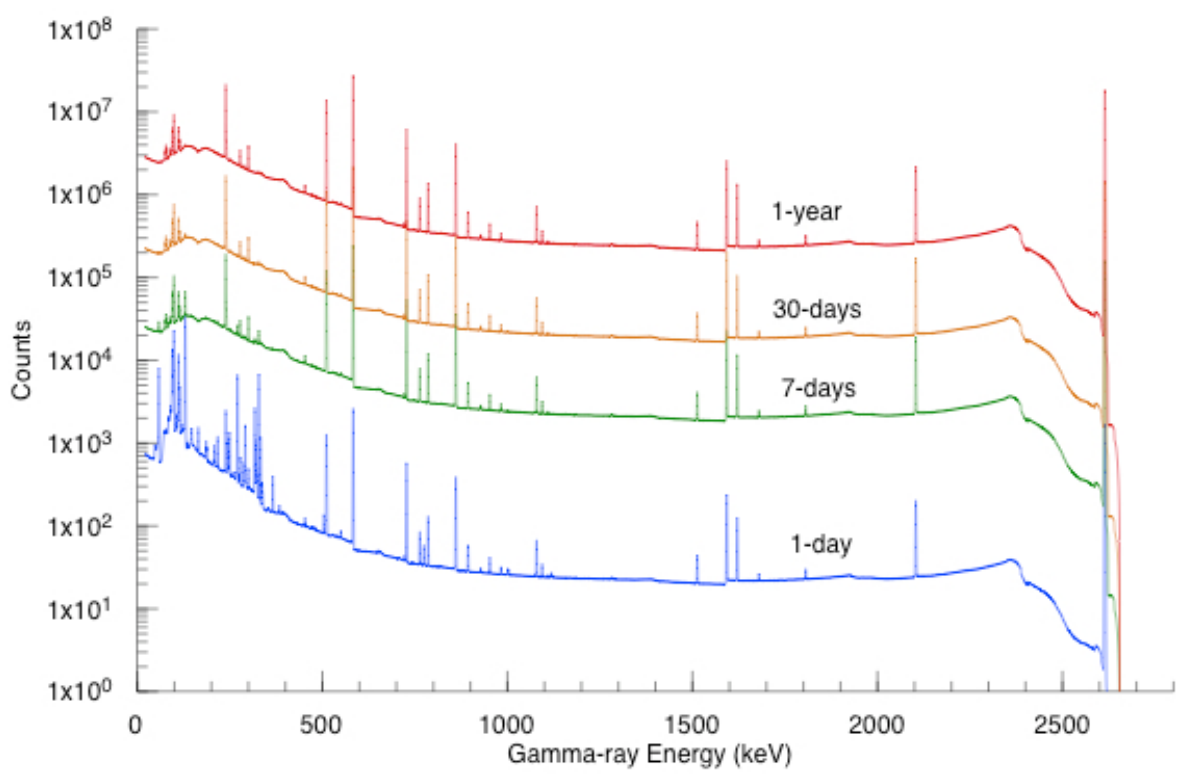

Fig. 11. Simulated 1000-s gamma-ray spectra from $5 \mathrm{~kg}$ of chemically separated uranium from discharged AWHR fuel containing $0.02 \%$ of parasitic ${ }^{232} \mathrm{U}$. We follow the evolution of the spectral structure as a function of time (1-d, 7-d, 30-d, and 1-year) following discharge. At 1-day, the bulk of the structure occurs below $400 \mathrm{keV}$. This structure becomes increasingly masked with the rapid ingrowth of a ${ }^{228} \mathrm{Th}$ spectrum with only uranium fluorescent K-series $\mathrm{X}$-rays that reveal that these spectra are from a uranium source.

Comparing the region below $300 \mathrm{keV}$ in the 1-y AHWR spectrum with the point source ${ }^{228} \mathrm{Th}$ spectrum in Fig. 6, self-attenuation is apparent and greater annihilation is notable in the AHWR spectrum from a 5-kg uranium sphere. Where the spectral structure differs between the uranium and thorium sources is below $120-\mathrm{keV}$ and shown in Fig. 12. In the ${ }^{228} \mathrm{Th}$ spectrum, we see strong $\mathrm{K} \mathrm{X}$-ray structure between 70- and 90-keV, largely from $\mathrm{Bi}$ and $\mathrm{Pb}$ $\mathrm{X}$-rays. These X-rays survive in the AHWR discharge spectrum as ${ }^{228} \mathrm{Th}$ is the daughter of ${ }^{232} \mathrm{U}$. However, in the AHWR discharge spectrum we observe the strong presence of uranium fluorescence K X-rays between 92 - and 111-keV that grow in concert with the increasing ${ }^{228} \mathrm{Th}$ spectrum that stimulates the uranium in the $5 \mathrm{~kg}$ sphere.

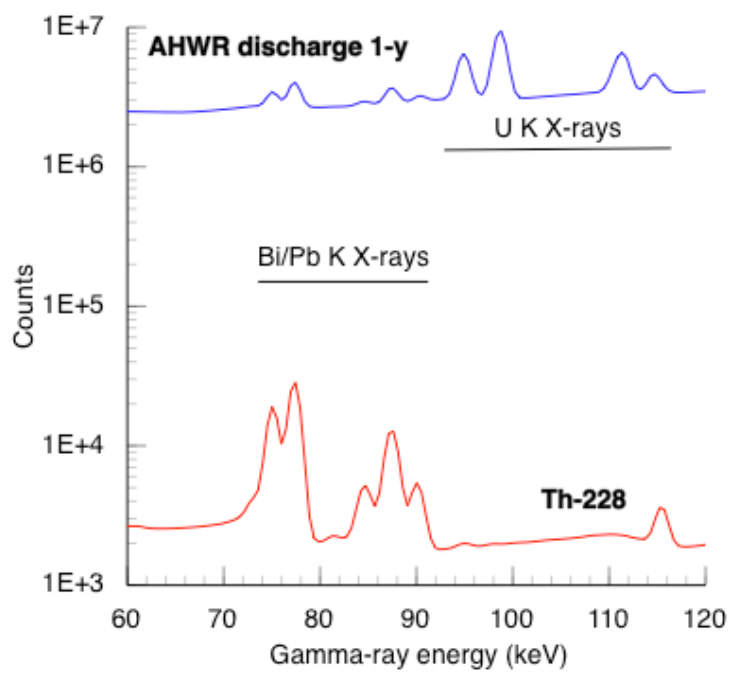

Fig. 12. The spectrum from AHWR discharge exhibits a strong ${ }^{228} \mathrm{Th}$ signature but differs from the ${ }^{28} \mathrm{Th}$ signature below $120 \mathrm{keV}$ with the presence of a pronounced uranium K X-ray structure. 


\section{Uranium-236-Reactor poison and oceanic fallout tracer}

Uranium-236 is neither fissile, nor very good fertile material but is generally considered a nuisance and long-lived radioactive waste. It is found in spent nuclear fuel and in reprocessed uranium made from spent nuclear fuel [44].

Uranium-236 as a reactor poison in a closed fuel cycle

The use of uranium re-enriched from spent reactor fuel (RU) in a closed fuel cycle was studied during the short-lived U. S. participation in the Global Nuclear Energy Partnership (GNEP) [46] between 2006 and 2009 [46]. The small amounts of 2.342E7-y 236U in RU would act as a poison and reduce the reactivity of the re-enriched reactor fuel $[48,49]$.

Investigating ocean currents using uranium-236

Knowledge of oceanic currents is important for understanding oceanic heat transport and therefore also important for climate research. In 2012, a team of Austrian and Australian scientists demonstrated the usefulness of $236 \mathrm{U}$ from fallout from nuclear testing in the $1950 \mathrm{~s}$ and 1960s as an oceanic tracer using yearly banding in coral cores. The team overcame the known difficulty of detecting this source by using the Vienna Environmental Research Accelerator's heavy-ion mass spectrometry system. It is the first ever annually resolved record of 236U from global fall-out. These cores can now be exploited as an oceanographic investigative tool for studying ocean currents $[50,[50,51]$.

\section{Uranium-237- Fissions with fast neutrons, production of heat-source ${ }^{238} \mathrm{Pu}$}

Uranium-237 is present in reprocessed uranium. When separated from the reprocessed uranium, its 6.75 -d half-life causes it to decay rapidly to $2.144 \mathrm{e} 6-\mathrm{y}{ }^{237} \mathrm{~Np} .{ }^{237} \mathrm{~Np}$ is used in the production of heat-source ${ }^{238} \mathrm{Pu}$.

${ }^{237} \mathrm{~Np}$ is a nuclide of considerable interest because it is also capable of sustaining a chain reaction with fast neutrons. Commercial nuclear reactors annually create tons of neptunium mixed in with other nuclear waste. Since 1999, the International Atomic Energy Agency in Vienna has urged monitoring of neptunium. However, according to the agency, the risk of anyone making neptunium bombs from that highly radioactive waste is low because it would be so difficult to extract the isotope 152].

Neptunium-237 is the progenitor of yet another decay series, the neptunium series. It undergoes alpha decay to ${ }^{233} \mathrm{~Pa}$. The gamma rays associated with this decay are too low in

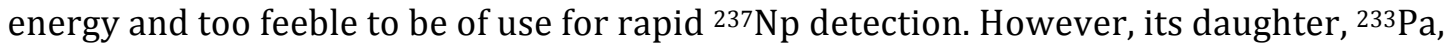
with a 225.97-d half-life grows rapidly into secular equilibrium and can act as a detection surrogate. It undergoes $\beta^{-}$decay with accompanying emission of relatively strong gamma rays at 300.34-, 312.17-, and 340.81-keV. The identity of neptunium would not be lost in the decay of a significant mass of ${ }^{237} \mathrm{~Np}$ with the production of $\mathrm{Np} \mathrm{K}$-series fluorescent X-rays. 


\section{Estimating uranium enrichment}

\section{Minimum enrichment estimation by peak-area ratio}

In principle, uranium enrichment can be determined by measuring the ratio of counts in the $185.71-\mathrm{keV} 325 \mathrm{U}$ peak and the $1001.03-\mathrm{keV}$ peak from the ${ }^{234} \mathrm{~Pa}$ granddaughter of $238 \mathrm{U}$. In the uranium spectra shown in Fig. 14, the increase in the height of the $186-\mathrm{keV} 235 \mathrm{U}$ peak relative to the $1001-\mathrm{keV}^{238} \mathrm{U}$ peak as a function of increasing enrichment is readily apparent.

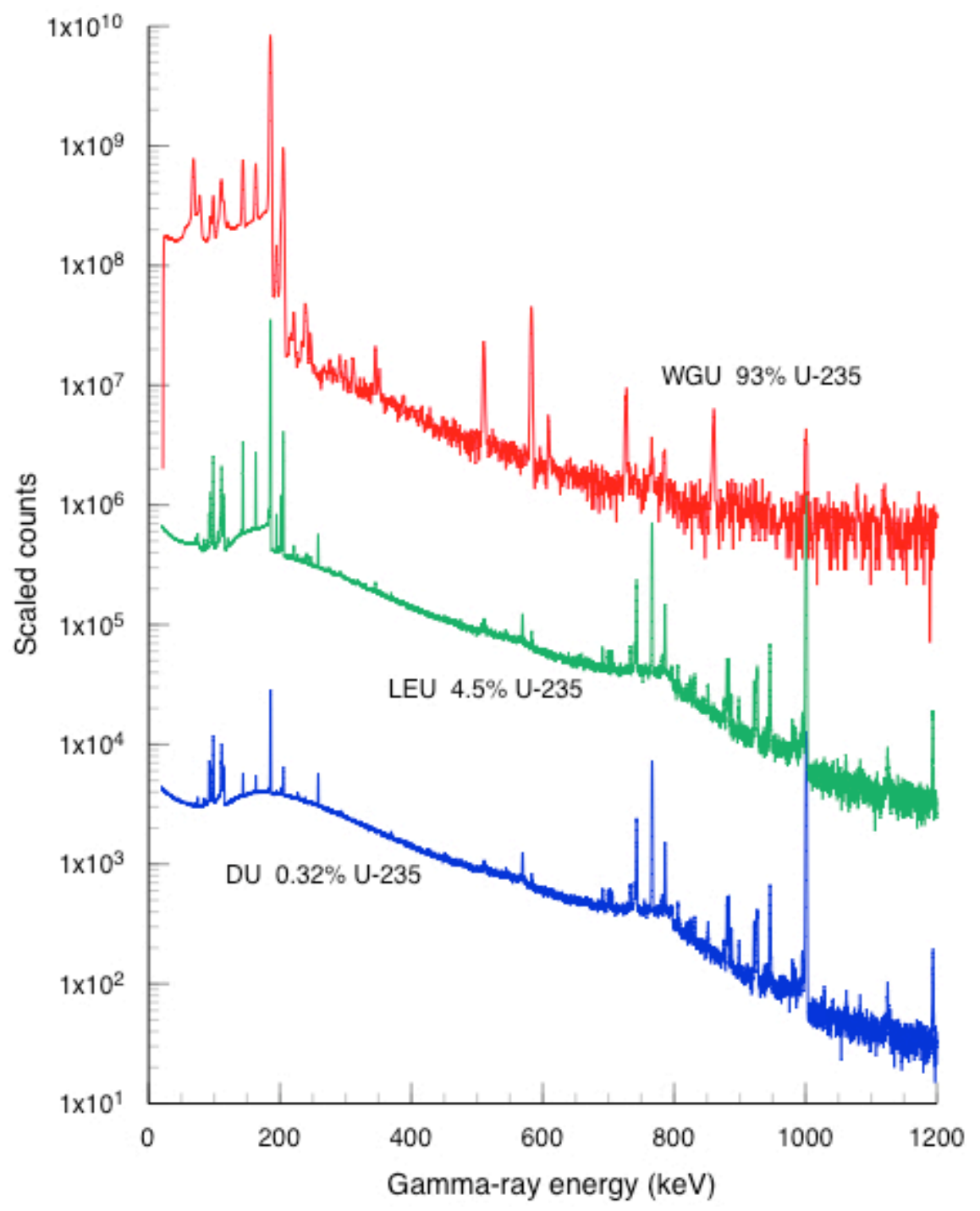

Fig. 14. Uranium spectra from standards of three different enrichments. The top two spectra have been scaled to separate them for presentation. All three were acquired with HPGe detectors of $20 \%$ relative efficiency at a source distance of $100 \mathrm{~cm}$. The lower two spectra were counted for $\mathbf{7 0 0 0}$ seconds. The upper spectrum, a weaker source, was counted for only 900 seconds. 
In the early 1970's an effort was made to apply this ratio to obtain high precision, high accuracy results. It was not found to be fruitful for this purpose because certain required information was unavailable for field use [53]. It has also been observed that although the 186- and 1001-keV peaks are easy to measure, it is difficult, because of the large difference in their energies, to determine the relative efficiencies with which they are detected [54].

Furthermore, if there is material intervening between the uranium and the detector, the $186 \mathrm{keV}$ peak will be preferentially attenuated relative to the $1001 \mathrm{keV}$ peak, resulting in an enrichment estimate that is too low, a lower limit or minimum estimate.

Our goal is considerably less ambitious in terms of precision and accuracy. We do, however, wish to make at least a rough estimate of minimum enrichment grade. The task is challenging: to be able to make this enrichment estimate with an automated analysis tool that doesn't require knowledge of the nature of the source, the source-to-detector measurement distance, or the efficiency of the detector. To do so, we have resorted to some sweeping assumptions that have led to solutions that are imprecise but we nevertheless find useful.

If $N_{x}$ is the number of atoms of isotope $x$ in a gram of uranium, then the number of counts from a particular gamma ray $C_{\gamma x}$ from that isotope observed by a detector at a distance $r$ in a counting interval $t_{x}$ is

$$
C_{\gamma x}=N_{x} \lambda_{x} I_{\gamma x} t_{x} \varepsilon_{\gamma x} \alpha_{x} \beta_{x}
$$

where $\lambda_{x}$ is the isotope decay constant, $I_{\gamma x}$ is the emission probability per decay of a particular gamma ray $\gamma, \varepsilon_{\gamma}$ is the detection efficiency for the gamma ray at distance $r, \alpha_{x}$ is an external absorber correction, and $\beta_{x}$ is a correction for sample self-absorption.

We note that the first three terms of Eq. 4 compute the specific emission rate $S_{\gamma x}(\gamma / \mathrm{s} / \mathrm{g})$ of the gamma ray. If we now measure a uranium item and take the ratio of the counts from the 185.7-keV gamma ray from ${ }^{235 \mathrm{U}}\left(C_{235}\right)$ and the counts from to $1001.03-\mathrm{keV}$ gamma ray from ${ }^{238} \mathrm{U}\left(C_{238}\right)$, we arrive at Eq. 5.

$$
\frac{C_{235}}{C_{238}}=\frac{S_{235}}{S_{238}} \cdot \frac{\varepsilon_{235}}{\varepsilon_{238}} \cdot \frac{\alpha_{235}}{\alpha_{238}} \cdot \frac{\beta_{235}}{\beta_{238}}
$$

where the subscripts 235 and 238 refer to quantities associated with the $186 \mathrm{keV}$ peak from

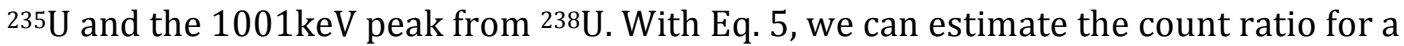
measurement of a uranium item of unknown enrichment. Evaluation of the four terms was done as follows.

1. We assume that the uranium items that we measure are not young, such that the ratio of specific gamma-ray emissions for the $186-\mathrm{keV}{ }^{235} \mathrm{U}$ gamma ray and the $1001-\mathrm{keV} 234 \mathrm{mPa}$ gamma ray remain invariant with time for any particular enrichment. Using our GamGen computer code [55], we computed these specific gamma ray emission rates for aged uranium at five enrichment grades [DU $(0.2 \%$ $\left.{ }^{235} \mathrm{U}\right), \mathrm{NU}(0.7 \%)$, LEU (5\%), HEU(20\%), and WGU (93\%)] . 
2. We measured gamma-ray standards of activity to determine the full-energy peak efficiency curves for HPGe detectors of $20 \%, 40 \%, 100 \%$, and $170 \%$ relative efficiency at a distance of 1 meter. From these curves we determined the detector efficiencies for the 185.7- and 1001.03-keV full-energy peaks for the four detectors. At this distance, count rates fall off closely to the inverse square of the source distance even for somewhat extended sources. This is true for distances somewhat less than 1 meter and somewhat more for some field measurements. For this reason, we have assumed that the efficiency ratio is independent of source distance.

3. With field measurements we can have no a priori knowledge of the presence and type of external absorbers, so we assume that none are present. This implies that $\alpha_{235} / \alpha_{238}=1$ and that Eq. 5 becomes Eq. 6 .

$\frac{C_{235}}{C_{238}}=\frac{S_{235}}{S_{238}} \cdot \frac{\varepsilon_{235}}{\varepsilon_{238}} \cdot \frac{\beta_{235}}{\beta_{238}}$

Differential attenuation through any absorbers that might actually be present would preferentially reduce the $185.7-\mathrm{keV}$ full-energy peak. As a result we can, at best, only estimate a minimum value for enrichment.

4. We also can have no a priori knowledge of the nature of the uranium item that is being measured. As a result, an accurate estimate of self-absorption cannot be computed. It is likely that the greatest self-absorption would occur with pure uranium metal and that is our assumption. Further, if we assume that the item is represented by a line source placed along the detector axis, we can do a simple integration of exponential attenuation to determine the self-absorption of a uranium item of thickness, $\tau$, which is likely to represent the maximum self-absorption that will be encountered. The integration leads us to Eq. 7 .

$$
\beta=A / A_{0}=\frac{1}{\mu \tau}\left(1-e^{-\mu \tau}\right)
$$

where $\mu$ is the linear attenuation coefficient of the item material $\left(\mathrm{cm}^{-1}\right), A_{0}$ is the total activity of the source and $A$ is the activity measured when one end of the source is situated at the detector face. To choose a value of $\tau$, we used Eq. 6 and 7 to compute the ratio of self-absorption in uranium for the 186- and 1001-keV gamma rays, as well as the ratio of the two, as a function of uranium thickness. These results are shown in Fig. 15.

In the figure there is a gentle "knee" at about $0.5 \mathrm{~cm}$ of uranium before the selfabsorption ratio is dominated by ${ }^{238} \mathrm{U}$. At $1.5 \mathrm{~cm}$ it is beginning to saturate so we set our value of $\tau$ at $1.5 \mathrm{~cm}$, a substantial $U$ thickness. We then computed Eq. 7 for the four detectors used for energy calibration to provide a rough estimate of the maximum range of self-absorption. 


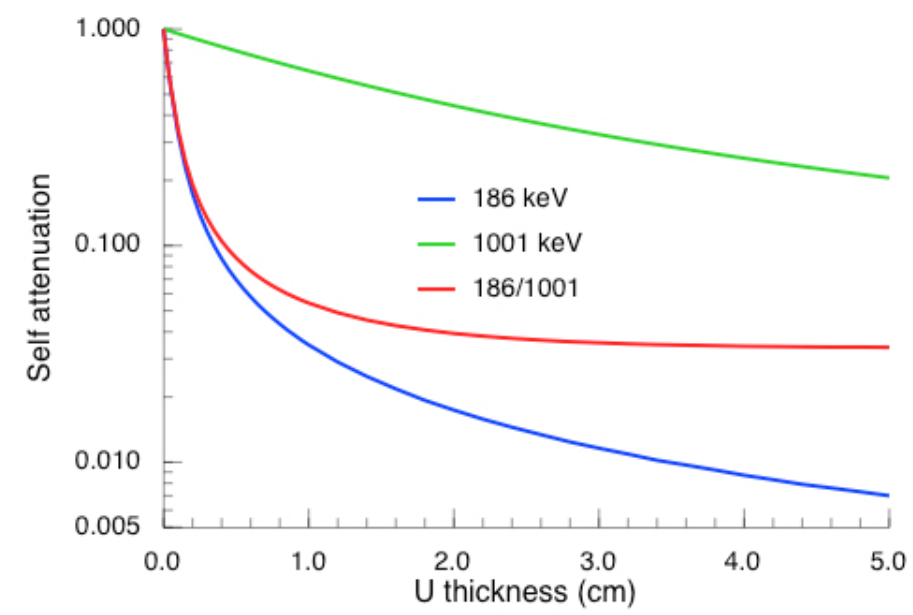

Fig. 15. Self-absorption of 185.7 and $1001.03-k e V$ gamma rays and their ratio in uranium metal

Fig. 16 shows the results of the calculations for $235 \mathrm{U}$ concentrations of $\mathrm{DU}$ at $0.18 \%$, natural uranium at $0.711 \%$, LEU at $5 \%$, borderline LEU/HEU at $20 \%$ and WGU at $93 \%$. Using the computed self-attenuation ranges as a guide, and some empirical adjustments as a diversity of experimental results were obtained, we divided the count ratios into six count-ratio zones, that allow us to estimate minimum enrichment grade from measured $185.7 / 1001.03-\mathrm{keV}$ count ratios. The vertical bars represent the self-attenuation range and result in overlap of some of the enrichment grade assignments, hence some ambiguity. The zone ranges and enrichment grade assignments are presented in Table 6.

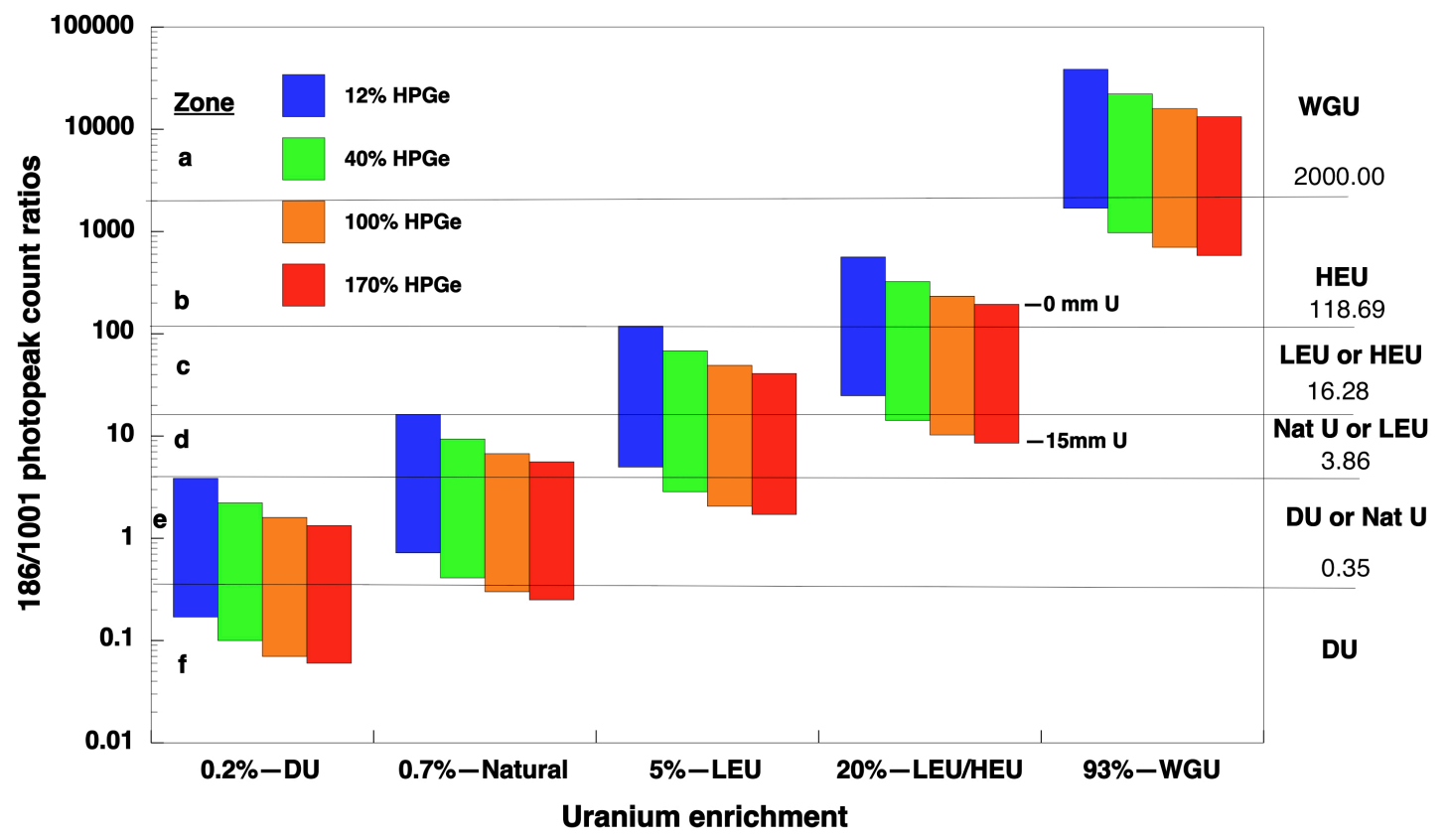

Fig. 16. 186/1001-keV photopeak ratio estimates for unshielded uranium as a function of enrichment, detector relative efficiency, and uranium thickness. 
Table 6. Assignment of enrichment grade using zone boundaries defined in Fig. 16.

\begin{tabular}{clr}
\hline Zone & Enrichment grade & 186/1001 count range \\
\hline $\mathrm{f}$ & DU & $<0.35$ \\
$\mathrm{e}$ & DU or NU & $0.35-3.86$ \\
$\mathrm{~d}$ & NU or LEU & $3.86-16.28$ \\
$\mathrm{c}$ & LEU or HEU & $16.28-118.70$ \\
$\mathrm{~b}$ & HEU & $118.70-2000.00$ \\
$\mathrm{a}$ & WGU & $>2000.00$ \\
\hline
\end{tabular}

While self-absorption preferentially attenuates the $185.7-\mathrm{keV}$ line, this is also true for external absorbers. Our self-absorption compensations extend over broad ranges of count ratios and are computed for self-absorption compensation only. Nevertheless, these broad ranges may be unintentionally helpful when external absorbers are present.

To test the utility of this approach we measured eight New Brunswick Laboratory (NBL) [56] thin-window certified reference materials of uranium enrichment and compared the material's certified enrichment grades to the grades determined by HPGe ID. These results appear in Fig. 17. The measurement results for the 186/1001-ratio for all of these standards fall neatly in the appropriate zones defined in Table 6. As the items increase in enrichment, we notice that they appear approximately linearly on the log-log plot up to $20 \%$. As the enrichment increases, the 1001 peak counts begin to diminish rapidly and rapidly increase the peak ratio.

Fig. 17 shows results of essentially bare sources. Sufficiently shielded items with 186-keV counts diminished relative to $1001-\mathrm{keV}$ counts would appear lower in the plot, falling into lower zones that would underestimate the enrichment.

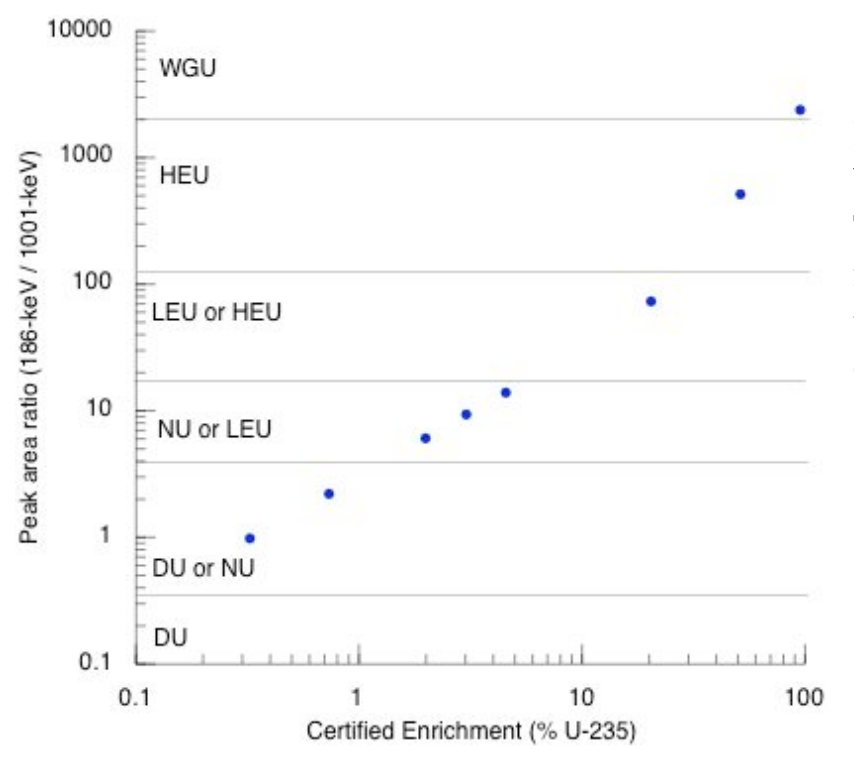

Fig. 17. A test of the enrichment grading by $186-\mathrm{keV} / 1001-\mathrm{keV}$ peak area ratio. The blue symbols indicate measured ratios from New Brunswick Laboratory uranium enrichment standards are correctly graded according to Table 6 . 


\section{Detecting HEU when no ${ }^{238} \mathrm{U}$ signal is manifest}

We analyzed a number of known WGU spectra in which the ${ }^{238} \mathrm{U}$ signature was not manifest to HPGe ID. However, the ${ }^{235} \mathrm{U}$ signature in these spectra was manifest with strong 143-, 163-, 186-, and 205-keV lines. WGU spectra from other sources can have a considerably larger ${ }^{232} \mathrm{U}$ content, leading to a large Compton continuum from its daughter ${ }^{208 \mathrm{Tl}}$ that masks the 1001-keV peak. Were these field spectra of unknown provenance then the measurement would be indicative that the measured items were lightly shielded. Light shielding and a strong $235 \mathrm{U}$ signature combined with the absence of a manifest $238 \mathrm{U}$ signature strongly suggest that the uranium is HEU with high ${ }^{235} \mathrm{U}$ content and, quite possibly, WGU.

\section{Detecting shielded HEU}

Because it can be used in the manufacture of nuclear explosives, illicit traffic in HEU is a matter of serious concern. Materials intervening between the detector and an HEU source will preferentially reduce the $235 \mathrm{U}$ signal, eliminating or greatly reducing the ability to make roughly accurate enrichment estimates by the peak ratio method. An alternative surrogate HEU signature might be that of ${ }^{232} \mathrm{U}$.

\section{Uranium-232: grasping at straws to detect shielded HEU}

With only a 69-year half-life, ${ }^{232} \mathrm{U}$ does not occur in nature but is introduced as a result of reactor irradiation of uranium resulting in a number of complex reaction and decay chains. Four of the most significant of these complex chains are [57]:

$$
\begin{aligned}
& { }^{235} \mathrm{U}(\alpha){ }^{231} \mathrm{Th}\left(\beta^{-}\right){ }^{231} \mathrm{~Pa}(\mathrm{n}, \gamma){ }^{232} \mathrm{~Pa}\left(\beta^{-}\right){ }^{232} \mathrm{U} \\
& { }^{234} \mathrm{U}(\alpha){ }^{230} \mathrm{Th}(\mathrm{n}, \gamma){ }^{231} \mathrm{Th}(\beta) \text { - }{ }^{231} \mathrm{~Pa}(\mathrm{n}, \gamma){ }^{232} \mathrm{U} \\
& { }^{235} \mathrm{U}(\mathrm{n}, \gamma){ }^{236 \mathrm{U}}(\mathrm{n}, \gamma){ }^{237} \mathrm{U}\left(\beta^{-}\right){ }^{237} \mathrm{~Np}(\mathrm{n}, 2 \mathrm{n}){ }^{236 \mathrm{~m} N \mathrm{~N}\left(\beta^{-}\right)}{ }^{236} \mathrm{Pu}(\alpha){ }^{232 \mathrm{U}} \\
& { }^{238} \mathrm{U}(\mathrm{n}, 2 \mathrm{n}){ }^{237} \mathrm{U}\left(\beta^{-}\right){ }^{237} \mathrm{~Np}(\mathrm{n}, 2 \mathrm{n}){ }^{236 \mathrm{~m}} \mathrm{~Np}\left(\beta^{-}\right){ }^{236} \mathrm{Pu}(\alpha){ }^{232 \mathrm{U}}
\end{aligned}
$$

Because uranium may contain ${ }^{236} \mathrm{U}$ as a result of the inclusion of previously reactorprocessed uranium, another reaction chain may also be important:

$$
{ }^{236} \mathrm{U}(\mathrm{n}, 2 \mathrm{n}){ }^{237} \mathrm{U}\left(\beta^{-}\right){ }^{237} \mathrm{~Np}(\mathrm{n}, 2 \mathrm{n}){ }^{236 \mathrm{~m}} \mathrm{~Np}\left(\beta^{-}\right){ }^{236} \mathrm{Pu}(\alpha){ }^{232} \mathrm{U}
$$

In the 1960's, uranium that had previously been irradiated in reactors was introduced into U.S. gaseous diffusion plants to be re-enriched. Consequently, trace quantities of $232 \mathrm{U}$ were entrained in the gaseous diffusion cascades where they remain today and became a minor contaminant in new feedstock as it was introduced to the cascade. It is believed that similar circumstances have occurred elsewhere. Evidence [58] also suggests that, during the enrichment process, the ${ }^{232} \mathrm{U}$ is preferentially swept into the light isotope fraction that becomes HEU and immeasurably small amounts go into the heavy isotope fraction that becomes depleted uranium. Therefore, the manifest presence of ${ }^{232} \mathrm{U}$ in uranium is consistent with that uranium being HEU or, more likely, WGU. 
The low energies and emission intensities of the gamma rays from decay of $232 \mathrm{U}$ prevents it from being readily detectable directly. Consequently, we rely on yet another surrogate, ${ }^{208} \mathrm{Tl}$, a distant radioactive daughter of $232 \mathrm{U}$ (Fig. 5) and a major contributor to the $228 \mathrm{Th}$ signature in Fig. 6. The decay of ${ }^{208} \mathrm{Tl}$ results in the emission of several gamma rays with strong intensities. Of most interest is the highly penetrating gamma ray at $2614.53-\mathrm{keV}$ with $99 \%$ emission intensity. While this gamma ray is readily detectable from HEU, its presence is not unique, so that, without elimination of other possible sources of this radionuclide, it could lead to misidentification of shielded HEU.

Fig. 18 indicates the presence of ${ }^{232} \mathrm{U}$ at $2615-\mathrm{keV}$ in a gamma-ray spectrum of WGU. The figure also illustrates this peak, from the Th decay series, in its background spectrum, scaled to the measurement time of the WGU spectrum, and taken when the WGU was absent from the laboratory. The $2615-\mathrm{keV}$ peak in the gross spectrum of the WGU sample shows an excess of counts above background, by about a factor of three, that is attributable to ${ }^{232} \mathrm{U}$.

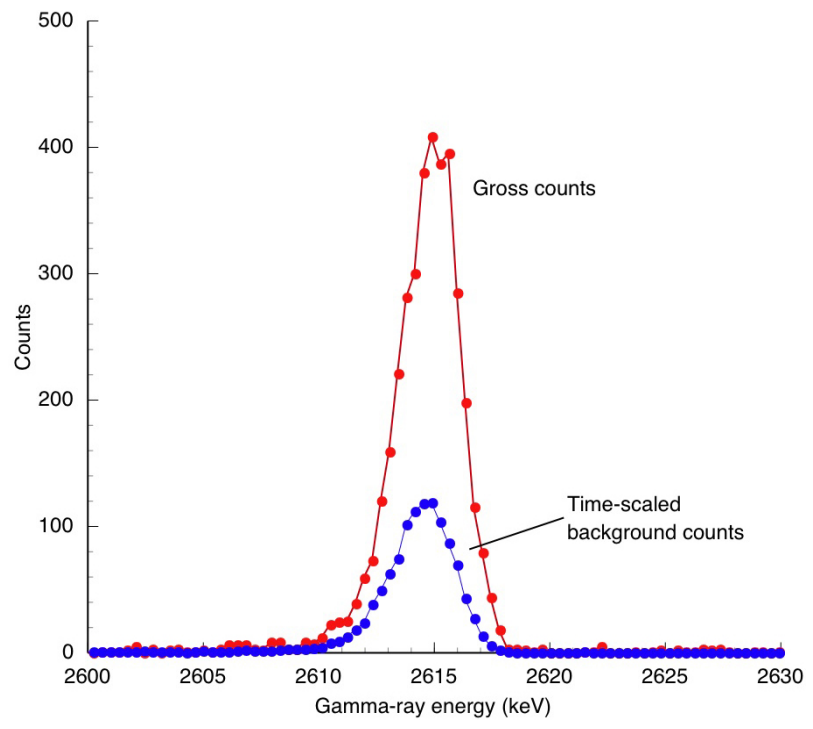

Fig. 18. The 2615-keV peaks in the spectra of background (blue) and the gross spectrum of WGU (red). The presence of ${ }^{232} \mathrm{U}$ is indicated by the excess counts above background in the WGU spectrum.

The simple fact that excess ${ }^{232} \mathrm{U}$ above background ${ }^{232} \mathrm{U}$ can be found in reprocessed uranium may be insufficient to infer that its presence alone is an indicator of the presence of shielded HEU. We may wonder if a shielding scenario could actually occur that would make an excess of the $2615-\mathrm{keV}$ gamma ray a likely inference of shielded HEU. To investigate this, we did some simple computer simulations of two shielding variations, with results from of an old benchmark study to guide us.

Many years ago we did a benchmark study to accurately model the HPGe detector gamma-ray spectrum from thick actinide sources [59]. As part of that study we used an HPGe detector with $29 \%$ relative efficiency to acquire a spectrum from a $3.15 \mathrm{~cm}$ radius $93 \%{ }^{235} \mathrm{U}$ sphere. And, subsequently, we measured a trustworthy overnight background 
spectrum that we time-scaled and subtracted from the foreground spectrum to obtain a net spectrum that revealed the excess $2615-\mathrm{keV}$ peak.

In the original study we modeled the sphere, with its declared isotopic vector (except for ${ }^{232} \mathrm{U}$ ), and its environs in detail with the MCNP 3-D Monte Carlo code [60] to obtain the gamma-ray flux at the detector face. We then convolved those results with a full-spectrum response function for our detector, determined with the method of Mitchell [61], to obtain a highly accurate simulation of the HPGe spectrum. Using this simulation we were able to determine the isotopic fraction of $232 \mathrm{U}$ at $0.100 \pm 0.001 \mathrm{ppb}$.

For this paper, we modeled the bare sphere with a 1-D-spherical deterministic code using a reasonable facsimile of the original geometry, the declared uranium isotopic vector, and the ${ }^{232} \mathrm{U}$ isotopic value determined by the original benchmark study. The modeled flux at the detector was convolved with a detector response model that we had on hand for a detector of $20 \%$ relative efficiency.

This was followed by two more models with Pb cladding to study the effect of the $186 / 1001$ peak-count ratio as a function of cladding thickness. If the sphere is shielded to avoid detection, the choice of lead as the shielding material is not entirely arbitrary. The desired criteria for such a shield would be high-Z, high density, low expense, easy obtainability, and, perhaps a low melting temperature for casting. Lead satisfies all of these criteria.

To estimate how much cladding would be needed to reduce the 186/1001-count ratio from bare $93 \%$ WGU to an apparent $20 \%$ borderline $235 \mathrm{U}$ HEU content value, we rearranged and repurposed Eq. 5 to study external shielding rather than self-absorption.

$$
\frac{C_{235}}{C_{238}}=\frac{S_{235}}{S_{238}} \cdot \frac{\varepsilon_{235}}{\varepsilon_{238}} \cdot \frac{\beta_{235}}{\beta_{238}} \cdot \frac{\alpha_{235}}{\alpha_{238}}
$$

Because we are using the same sphere in every simulation, the specific gamma-ray emission rates are constant as are the self-absorption terms. Further, because we are using the same detector for every simulation, the efficiency ratio remains constant. Therefore Eq. 13 reduces to Eq. 14.

$$
\frac{C_{235}}{C_{238}}=k \cdot \frac{\alpha_{235}}{\alpha_{238}}
$$

where $k$ is a constant of proportionality. We now return to our model of a line source placed along the detector axis and Eq. 14 becomes Eq. 15.

$$
\frac{C_{235}}{C_{238}}=k \cdot \frac{e^{-\mu_{235} x}}{e^{-\mu_{238} x}}
$$

Where the $\mu$-values are the linear attenuation coefficients for 186- and 1001-keV gamma rays in $\mathrm{Pb}$ and $x$ is the $\mathrm{Pb}$ thickness. We note that when the material is bare, $x=0$, the exponential term is unity, and $k$ is the count rate ratio. We have measured the count rate ratios for standards of 20\%- and 93\%-material (Fig. 17) with a portable HPGe detector and found the $k$-values to be 74 and 2388. We inserted these values into Eq. 15 and computed 
the count rate ratio for these two enrichments as a function of $\mathrm{Pb}$ thickness as shown in Fig. 19.

With increasing $\mathrm{Pb}$ cladding, the count rate ratio descends exponentially. With a cladding of $2.4 \mathrm{~mm}$, the count ratio for WGU is roughly equal to that of bare uranium of $20 \%$ enrichment. Using the uranium isotopic vector of the sphere $\left(0.1 \mathrm{ppb}^{232} \mathrm{U}, 1.00 \%{ }^{234} \mathrm{U}\right.$, 93.30\% ${ }^{235 \mathrm{U}}, 0.60 \%{ }^{236} \mathrm{U}$, and $5.10 \%{ }^{238 \mathrm{U}}$ ), we computed our HPGe spectral simulations for bare WGU and for WGU with $2.4 \mathrm{~mm}$ Pb cladding. These are shown in Fig. 20 overlaid on the original net measured spectrum for comparison.

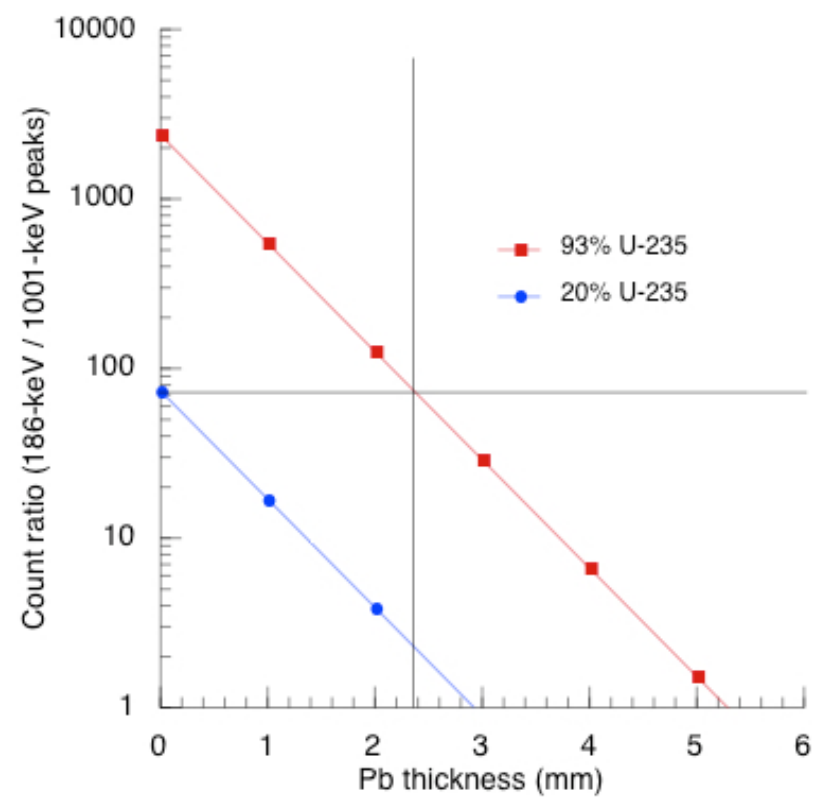

Fig. 19. The approximate expected 186- to $1001-\mathrm{keV}$ peak count ratio as a function of $\mathrm{Pb}$ cladding thickness over a WGU sphere. The crosshairs indicate the WGU count ratio when it descends as a function of classing thickness to the value equivalent to a bare sphere of $20 \%$ uranium enrichment and its corresponding $\mathrm{Pb}$ thickness of about $2.4 \mathrm{~mm}$ at this count ratio.

Fig. 20 shows the 1-D models of the HPGe spectrum from a WGU sphere superimposed on the net measured spectrum and scaled slightly for registration with the measured spectrum at $186 \mathrm{keV}$. We included the measured net spectrum from the old study as a qualitative check on the new computation. The older spectrum was taken with a more efficient detector and exhibited less downscatter, particularly at low energies. In the computed spectra, the expected dramatic reduction in counts at low energies appears and only the modest expected reduction at higher energies. 


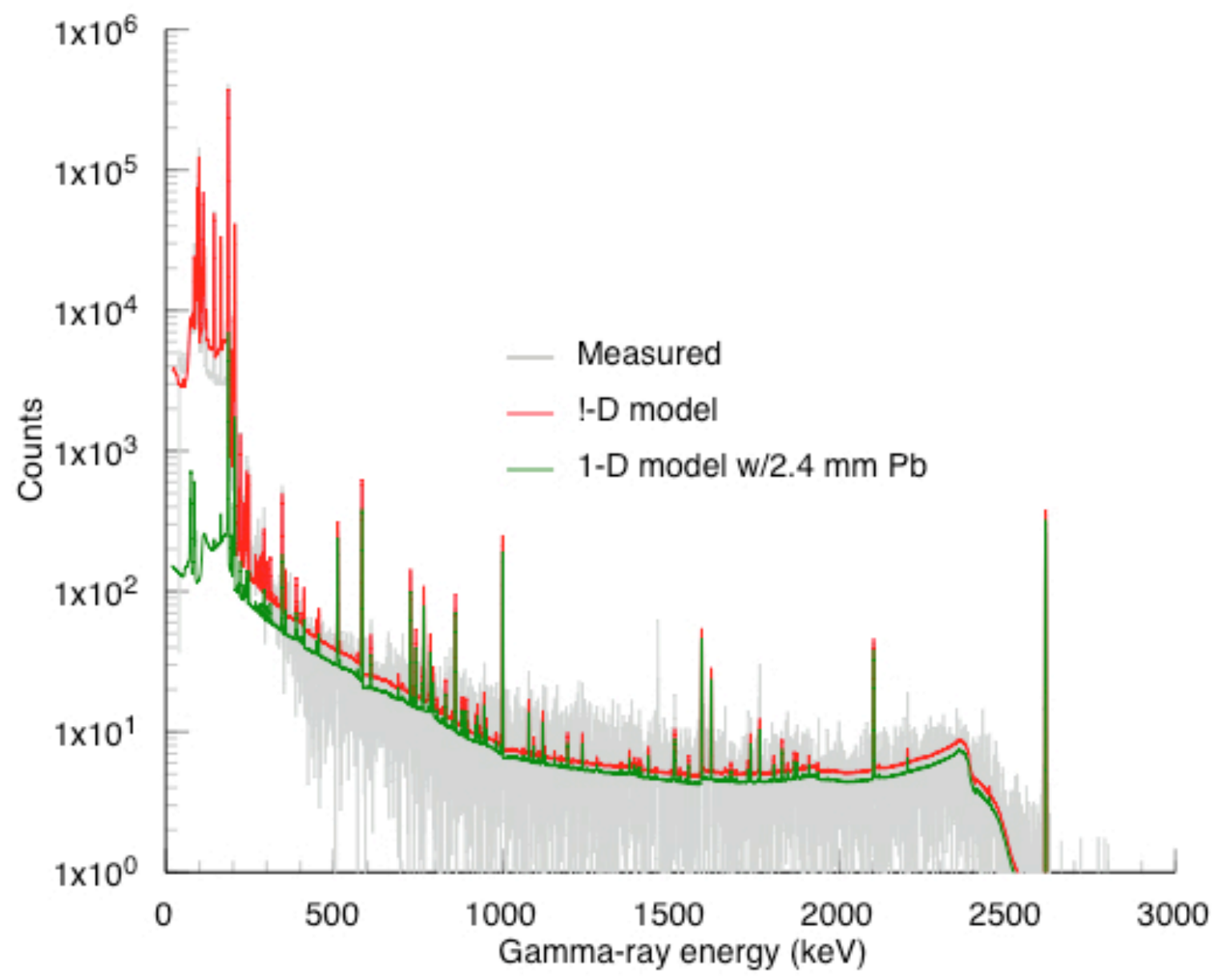

Fig. 20. 1-D models of the HPGe spectrum from a WGU sphere superimposed on a net measured spectrum. The unshielded 1-D model closely conforms to the measured spectrum with greater downscatter at low energies. The 1-D model with $2.4 \mathrm{~mm}$ Pb cladding shows a dramatic drop in low-energy counts and modest decreases at higher energies. 
In Fig. 21 we expanded the low-energy portion of Fig. 20 for a closer examination.

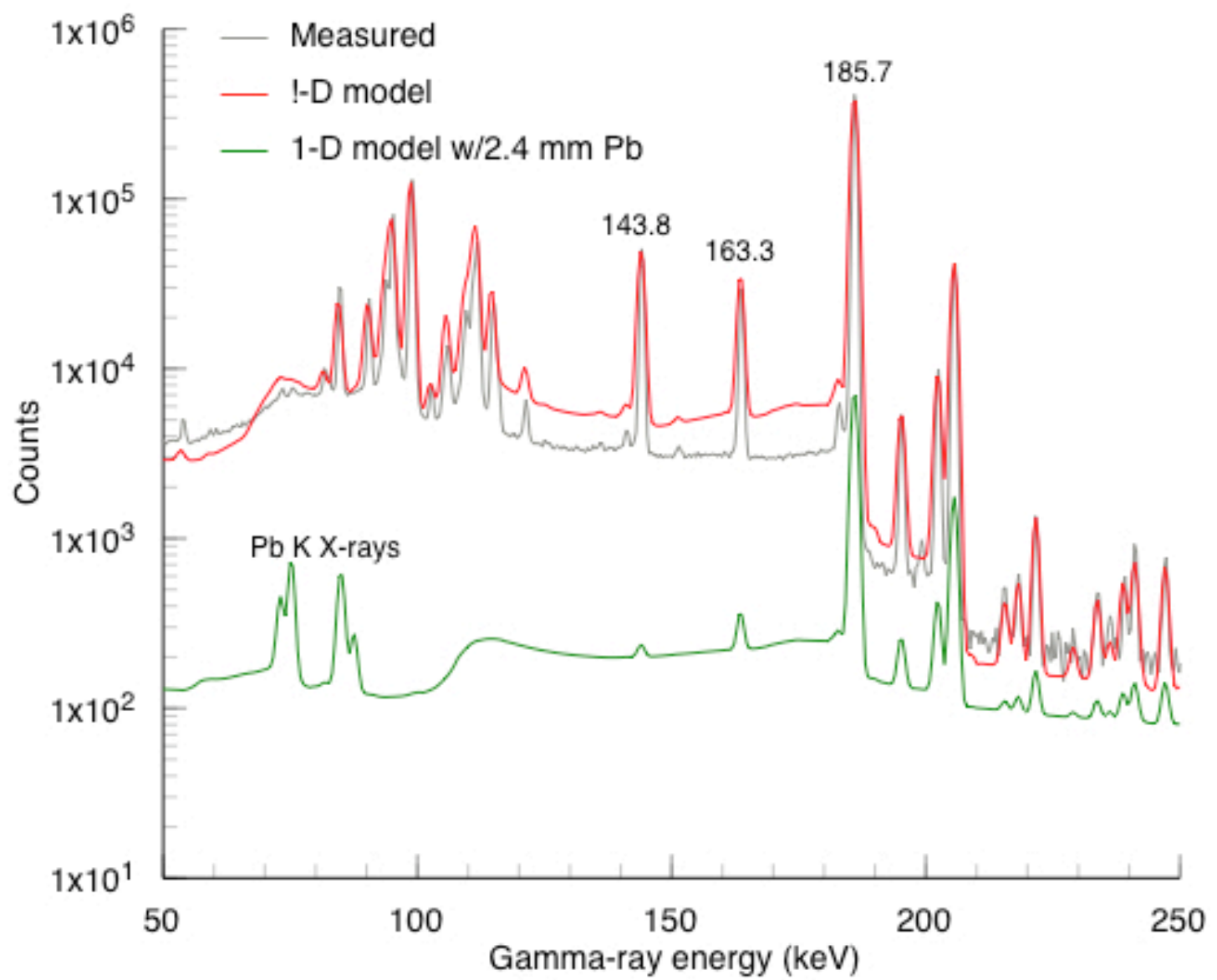

Fig. 21. Expanded view of the low-energy portion of the spectral plots in Fig. 20. The 1-D model indicates the increased downscatter in the modeled smaller detector. When the $2.4 \mathrm{~mm}$ Pb cladding was added, the spectrum was attenuated about two orders of magnitude in this region. Complete attenuation of the Th $\mathrm{K} X$-rays and low-energy ${ }^{235} \mathrm{U}$ peaks and the 120.9 -keV peak from ${ }^{234} \mathrm{U}$ has occurred. $\mathrm{Pb} \mathrm{X}$-ray fluorescence stimulated by ${ }^{235} \mathrm{U}$ radiation indicates the presence of the $\mathrm{Pb}$ cladding.

HPGe ID analyses of the computed spectra indicate that the unshielded model is WGU and the model with $2.4 \mathrm{~mm}$ shielding was determined to be " $U-235$, LEU or HEU or shielded $W G U$," consistent with the fact that $20 \%$ enrichment is borderline between LEU and HEU. A second model computed with $3 \mathrm{~mm}$ Pb cladding (not shown) and analyzed with HPGe ID correctly gave the result " $U-235, N U$ or $L E U$ weak or shielded." In both cases, the ${ }^{235} \mathrm{U}$ signature was manifest and would invite very close scrutiny by nuclear incident responders. 
What can we learn from Figs. 20 and 21?

1. A thin shield (2.4 $\mathrm{mm} \mathrm{Pb}$ ) will reduce the $185.7-\mathrm{keV}$ peak height by about a factor of 50 but the ${ }^{235} \mathrm{U}$ signal is still manifest. Doubling the cladding thickness would reduce the $185.7 \mathrm{keV}$ peak by another factor of about 50 .

2. Severe differential attenuation of the four principal $235 \mathrm{U}$ peaks at 143.2-, 163.4-, 185.7=, and 201.3-keV, is quite evident in Fig. 21. Of these, the two most likely to be manifest and testable in a like shielding situation, are the peaks at 185.7- and 205.3-keV.

3. The presence of the $\mathrm{Pb}$ cladding was announced by the Pb K-series X-ray fluorescence and provides further credence of significant shielding.

Nevertheless, our model is unrealistic in a number of ways:

1. It does not include background radiation.

2. It is deterministic and doesn't include statistical "jitter."

3. It was convenient to use known data to generate the model but the original sphere is unrealistically small with a mass of only $2.2 \mathrm{~kg}$, while the IAEA significant quantity for HEU ( $235 \mathrm{U} \geq 20 \%$ ) is $25 \mathrm{~kg}$ [62]. A $25 \mathrm{~kg}$ uranium sphere would increase the $235 \mathrm{U}$ signature strength by about a factor of 7 .

4. A less unrealistic model would be a $25 \mathrm{~kg}$ sphere. A $10 \mathrm{~mm}$ Pb-clad would only add about $2.5 \mathrm{~kg}$ to the mass, not likely an undue penalty.

5. Furthermore, a variety of other geometries and shielding could be used.

Beyond these obvious considerations, if this issue merits a more thorough study, our simple model is clearly insufficient.

Distinguishing between ${ }^{232} \mathrm{U}$ and ${ }^{232} \mathrm{Th}$

Just what can be inferred from the presence of $228 \mathrm{Th}$ in a gamma-ray spectrum is quite ambiguous. The most likely inference is that it is from background radiation (i.e. that portion originating from ${ }^{232} \mathrm{Th}$ ). The second most likely is that it is from NORM or TENORM containing ${ }^{232} \mathrm{Th}$. For example, thorium metal is also used as a hardener for magnesium alloys. A tungsten alloy with $2 \%$ thorium [63] is used for welding electrodes. Thorium oxide is a constituent of some optical glasses. Rarely encountered nowadays are gas lantern mantles infused with thorium nitrate.

A distinguishing signature for ${ }^{232} \mathrm{Th}$ that has aged a month or more since chemical purification are gamma rays, particularly at 911-keV (Fig. 7) emitted in the decay of its granddaughter ${ }^{228} \mathrm{Ac}$. Because ${ }^{232} \mathrm{U}$ is located in a collateral decay series that converges with

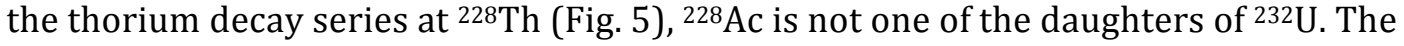
presence of the $911-\mathrm{keV}$ gamma ray is therefore a telltale that indicates presence of $232 \mathrm{Th}$ and not ${ }^{232} \mathrm{U}$.

As a further caution, we note that the production of TENORM, as in the case of gas lantern mantles, can entail some chemical purification of thorium which results in the presence of ${ }^{228} \mathrm{Th}$ but not, at least initially, ${ }^{228} \mathrm{Ac}$ with its telltale $911-\mathrm{keV}$ gamma ray. This is because before subsequently decaying to ${ }^{228} \mathrm{Ac}$. it takes a while before sufficient ${ }^{228} \mathrm{Ra}$ has decayed so that enough of its daughter ${ }^{228} \mathrm{Ac}$ has accumulated to make its $911-\mathrm{keV}$ gamma ray manifest. 
So, an identification of $228 \mathrm{Th}$, without the $911-\mathrm{keV}$ gamma ray, would only inconclusively be indicative of the presence of ${ }^{232} \mathrm{U}$.

Here is at least one case in which background radiation has an important use, that is to determine that the ${ }^{208} \mathrm{Tl}$ in the foreground spectrum is in excess above background and might be attributed to ${ }^{232} \mathrm{U}$ as an indication of the presence of HEU. If this criterion is satisfied, however, it must be kept in mind that the excess ${ }^{208} \mathrm{Tl}$ signature is possibly from young ${ }^{232} \mathrm{Th}$. 


\section{Further distinguishing between natural $\mathrm{U}$ and processed $\mathrm{U}$}

An important characteristic that we investigate is whether the uranium being measured is natural or processed material. If we've already established that the uranium enrichment determination by HPGe ID is not natural but is unambiguously DU or LEU or higher, then it has obviously been processed and the methods discussed here will be supplementary. If our Peak-area enrichment estimate falls in the ambiguous zones (DU or NU) or (NU or LEU) in Table 6, we may still be able to distinguish between processed and unprocessed uranium by

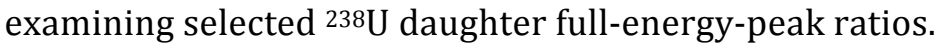

\section{The 609/1001 peak-area ratio}

As already noted, significant ingrowth of $234 \mathrm{mPa}$ in processed uranium occurs in only a few weeks. Decay of $234 \mathrm{mPa}$ produces gamma rays at 1001.03 - and $766.38-\mathrm{keV}$ that provides the most significant signature for the presence of $238 \mathrm{U}$.

In the foreground spectra from natural uranium, the most intense gamma ray from the distant daughters of $238 \mathrm{U}$ is the $609.31-\mathrm{keV}$ peak following the decay of ${ }^{214} \mathrm{Bi}$. The $1001-\mathrm{keV}$ peak also appears from background radiation but may be too weak, in a given spectrum, to be manifest. As a result we can expect that the ratio of the counts in the $609-\mathrm{keV}$ peak to the counts in the $1001-\mathrm{keV}$ peak from the decay of $234 \mathrm{mPa}$ in processed uranium to be high if determinable at all. ${ }^{5}$ This is reflected in the blue bar measurement results in the 609/1001column in Fig. 22.

In a foreground spectrum from processed uranium, the 609-keV peak will only be present from background ${ }^{214} \mathrm{Bi}$ as the long half-life of ${ }^{234} \mathrm{U}$ (Fig. 4) significantly retards sufficient ingrowth of the distant ${ }^{238} \mathrm{U}$ daughters in processed uranium for decades. The $1001-\mathrm{keV}$ peak that appears weakly in background radiation is enhanced relative to the $609-\mathrm{keV}$ peak with the presence of a processed uranium source. As a result the ratio of the $609-\mathrm{keV}$ peak to the $1001-\mathrm{keV}$ peak in processed uranium can be expected to be lower that in natural uranium as reflected in the brown bar measurement results in Fig. 22.

\section{The 1001/766 peak-area ratio}

Because the $766-\mathrm{keV}$ and $1001-\mathrm{keV}$ peaks are emitted by the same nuclide, we would initially expect that this ratio would be constant. However, as illustrated in Fig. 10, in natural uranium radiation, the $766.41234 \mathrm{mPa}$ peak forms a doublet with the $768.38-\mathrm{keV}$ peak from ${ }^{214} \mathrm{Bi}$. We integrate the counts in the doublet to substitute for the $766-\mathrm{keV}$ peak alone. This leads to a considerably increased ratio value that allows us to discriminate between natural and processed uranium. Data from the same four spectra used to compute the 609/1001-ratio for natural material produced the blue bar in the right-hand column of Fig. 22.

${ }^{5}$ HPGe ID can only compute a peak-area ratio when both of the peaks are manifest; otherwise the ratio is indeterminable. 
Determinable values of this ratio from available foreground measurements of processed uranium were obtained mostly from DU to LEU material, as both the 1001- and 766-keV peaks are relatively weak in highly enriched material. The short brown bar in the righthand column of Fig. 22 represents the extent of 14 measurements of processed uranium, three of which were used to produce the 609/1001-ratio result. The spread in the expected constant value is from wide variation in counting statistics

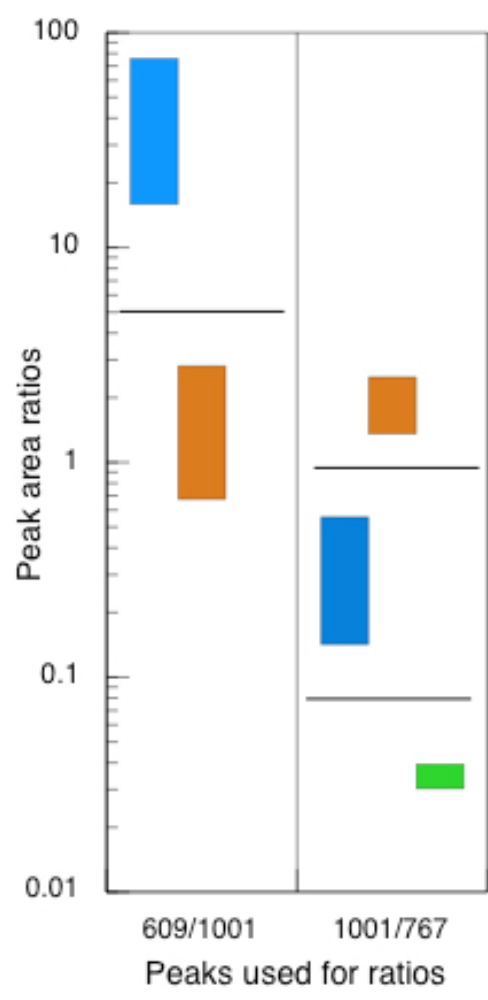

Natural U

Processed U

Pu-238

Fig. 22. Ratios of gamma-ray lines that can indicate whether uranium is natural or processed or whether ${ }^{238} \mathrm{Pu}$ is present. The black dividers in the figure indicate the threshold values used for testing the ratios. 


\section{Uranium-232 and apparent uranium-238 in plutonium}

\section{${ }^{232} \mathrm{U}$ in weapons-grade Pu}

We note that three of the known production methods for ${ }^{232} \mathrm{U}$ (Eqns. 10, 11, and 12) include the intermediate production of 2.9-y 236Pu. Production of weapons-grade $\mathrm{Pu}$ will also produce a trace amount of ${ }^{236} \mathrm{Pu}$. Therefore the gamma-ray spectrum of weapons-grade $\mathrm{Pu}$ that has aged for a few years will also exhibit the ${ }^{208} \mathrm{Tl}$ gamma rays that are indicative of the presence of ${ }^{228} \mathrm{Th}$. The presence of $232 \mathrm{U}$ is more likely to be an indicator of shielded HEU than of WGPu because shielded HEU will only exhibit the ${ }^{232} \mathrm{U}$ signature while, WGPu, unless very heavily shielded, will exhibit the $414-\mathrm{keV}$ gamma ray from ${ }^{239} \mathrm{Pu}$ as well as the 2615 $\mathrm{keV}{ }^{208} \mathrm{Tl}$ gamma ray. The presence of ${ }^{239} \mathrm{Pu}$ does not mean that HEU is absent but that its presence cannot be confirmed with the ${ }^{208} \mathrm{Tl}$ gamma ray because, in this case, the signature is an ambiguous situation that, nevertheless, points to the possibility that HEU or Pu or both, are present.

\section{${ }^{232} \mathrm{U}$ in reactor-grade $\mathrm{Pu}$}

Reactor-grade $\mathrm{Pu}$ is found in spent reactor fuel with significant burnup. This leads to transmutation of uranium isotopes into a number of plutonium isotopes, including ${ }^{238} \mathrm{Pu}$, ${ }^{239} \mathrm{Pu},{ }^{240} \mathrm{Pu},{ }^{241} \mathrm{Pu}$, and ${ }^{242} \mathrm{Pu}$ with the ${ }^{240} \mathrm{Pu}$ content exceeding $19 \%$. Often overlooked is the production of $236 \mathrm{Pu}$ [64] that, in terms of weight fraction, is a trace quantity but its relatively short half-life, 2.9-y, gives it high specific activity that is strongly manifest in the RGPu gamma-ray spectrum. The alpha decay of ${ }^{236} \mathrm{Pu}$ leads to ${ }^{232} \mathrm{U}$ that, in turn decays to ${ }^{228} \mathrm{Th}$ that produces a strong ${ }^{228} \mathrm{Th}$ signature.

\section{Heat-source plutonium}

Heat from the alpha decay of substantial quantities of relatively short-lived ${ }^{238} \mathrm{Pu}(87.7 \mathrm{y})$ is used as the energy source for a variety of Radioisotope Thermoelectric Generators (RTG). RTG's have been used as power sources for satellites, remote space probes, the Curiosity planetary rover [64], unmanned remote facilities, and, in the past, for nuclearpowered cardiac pacemakers $[66,67,68]$. The intense heat generated by ${ }^{238} \mathrm{Pu}$ is evident in Fig. 23.

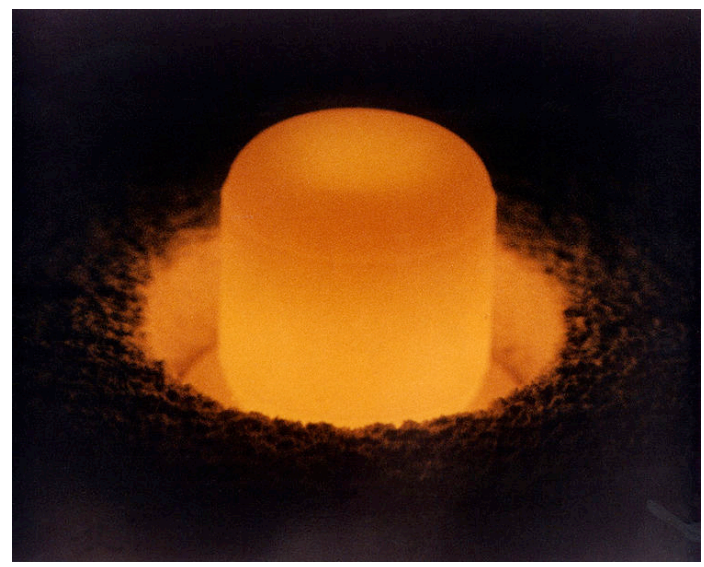

Fig. 23. A plutonium heat source glowing incandescent from ${ }^{238} \mathrm{Pu}$ decay heat. (Image from U.S. Department of Energy [69]). 
Heat-source ${ }^{238} \mathrm{Pu}$ is usually produced by neutron irradiation of ${ }^{237} \mathrm{~Np}$ recovered from spent nuclear fuel. This results in fewer undesirable $\mathrm{Pu}$ isotopes.

Nevertheless, the process does produce some parasitic ${ }^{236} \mathrm{Pu}$ and ${ }^{239} \mathrm{Pu}[70]$.

$$
\begin{aligned}
& { }^{237} \mathrm{~Np}(\mathrm{n}, \gamma){ }^{238} \mathrm{~Np}\left(\beta^{-}\right){ }^{238} \mathrm{Pu}(\mathrm{n}, \gamma){ }^{239} \mathrm{Pu} \\
& { }^{237} \mathrm{~Np}(\mathrm{n}, 2 \mathrm{n}) \operatorname{or}(\gamma, \mathrm{n}){ }^{236} \mathrm{~Np}\left(\beta^{-}\right){ }^{236} \mathrm{Pu}
\end{aligned}
$$

Production of ${ }^{238} \mathrm{Pu}$ from ${ }^{241} \mathrm{Am}$ is also possible but will also produce parasitic ${ }^{242} \mathrm{Pu}$ [70].

$$
\begin{aligned}
& { }^{241} \mathrm{Am}(\mathrm{n}, \gamma){ }^{242} \mathrm{Am}\left(\beta^{-}\right){ }^{242} \mathrm{Cm}(\alpha){ }^{238} \mathrm{Pu} \\
& { }^{241} \mathrm{Am}(\mathrm{n}, \gamma){ }^{242} \mathrm{Am}\left(\beta^{+}\right){ }^{242} \mathrm{Pu} \\
& { }^{241} \mathrm{Am}(\mathrm{n}, \gamma){ }^{242 \mathrm{~m}} \mathrm{Am}(\mathrm{IT}){ }^{242} \mathrm{Am}\left(\beta^{+}\right)^{242} \mathrm{Pu}
\end{aligned}
$$

\section{Plutonium-238-Plutonium masquerading as ${ }^{238} \mathrm{U}$}

The alpha decay of ${ }^{238} \mathrm{Pu}$ to ${ }^{234} \mathrm{U}$ populates the same excited states that emit 766.41- and 1001.03-keV gamma rays that we use to identify the presence of $238 \mathrm{U}$ from the decay of $234 \mathrm{mPa}$. The emission intensities of these two gamma rays from decay of ${ }^{238} \mathrm{Pu}$ are extremely low (Table 4) and will only be manifest in gamma-ray spectra from intense sources with high ${ }^{238} \mathrm{Pu}$ content. These conditions can occur with reactor-grade $\mathrm{Pu}$ and heat-source $\mathrm{Pu}$ and their presence could lead to misidentification of $238 \mathrm{U}$. However, the measured ratios of the 766.41- and 1001.03-keV gamma rays are easily differentiated from the ratios from natural and processed uranium. The relatively low fraction of $238 \mathrm{Pu}$ in fuel-grade $\mathrm{Pu}$ may make detection of these two gamma rays unreliable.

Fig. 24 illustrates spectra from RGPu and ${ }^{237} \mathrm{~Np}$-produced heat-source ${ }^{238} \mathrm{Pu}$. The 766 - and $1001-\mathrm{keV}$ gamma rays are called out in both spectra. The presence of ${ }^{236} \mathrm{Pu}$ is also evident in the heat-source spectrum, again leading to a strong ${ }^{228} \mathrm{Th}$ signature. Plutonium-239 is evident in the heat source spectrum by the presence of the 375 - and $414-\mathrm{keV}$ peaks that are quite small in the scale of the plot. 


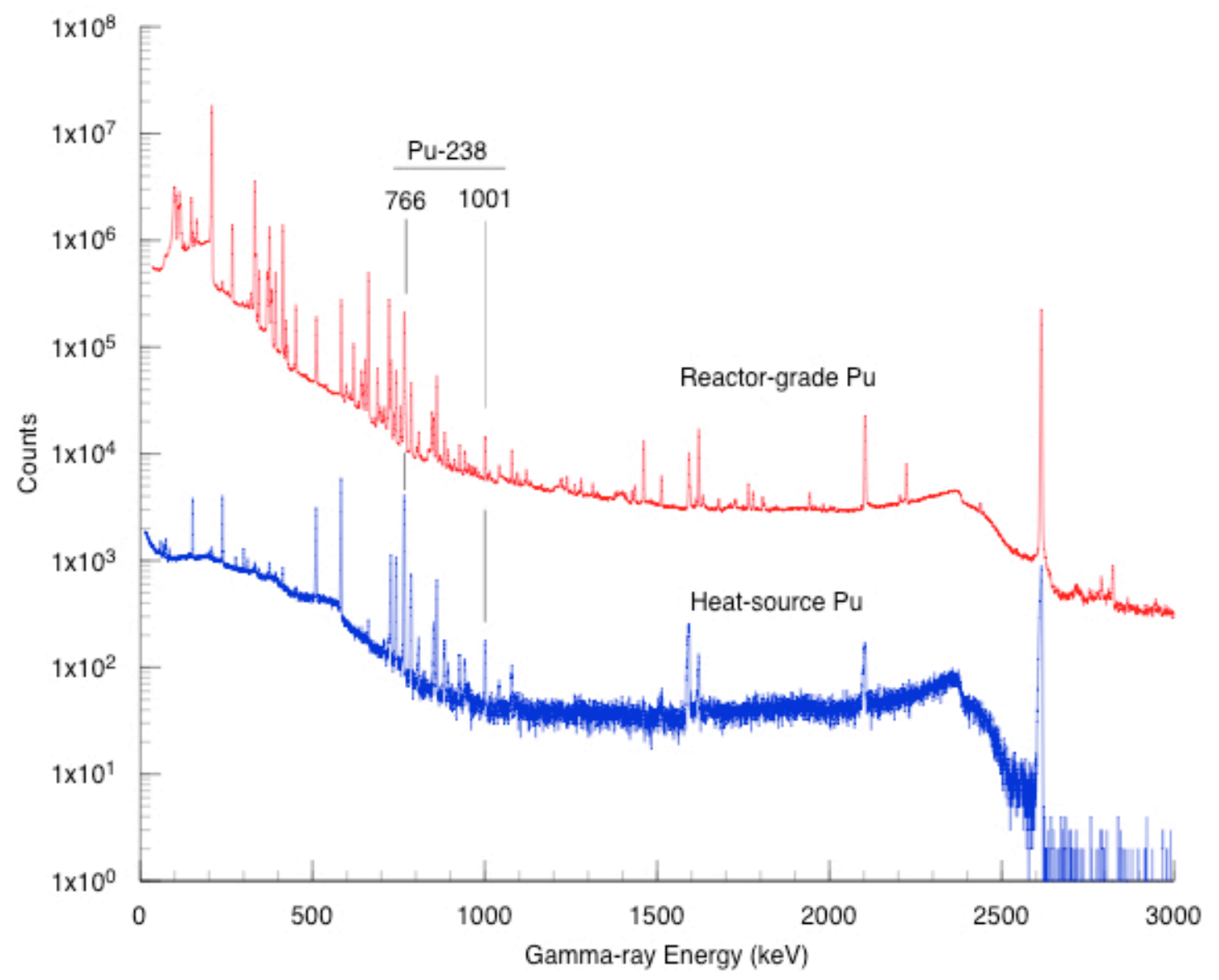

Fig. 24. HPGe spectra from reactor-grade $\left(30 \%{ }^{240} \mathrm{Pu}\right)$ and heat-source $\mathrm{Pu}$ with the 766 - and $1001-\mathrm{keV}$ peaks called out that could lead to misidentification of ${ }^{238} \mathrm{U}$. The presence of parasitic ${ }^{236} \mathrm{Pu}$ is also evident in both spectra from by the ${ }^{228} \mathrm{Th}$ signature. 


\section{Conclusion}

Uranium in its variety of forms, enrichments, and appearance in two reactor fuel cycles presents a challenge to rapidly and unambiguously identify its presence and its qualitative attributes from field measurements. We began this paper with a sketch of the behavior of our expert system that exploits heuristics to produce these results for uranium and similar, but less complicated results for more than 200 other radioactive sources. Following that description, we led the reader along selected pathways in the labyrinth of actinide element creation and decay, pausing to examine the salient radiation signatures of the uranium isotopes, their daughters, and others that can interfere with uranium detection and characterization.

HPGe ID is most closely focused on identifying illicit fissile materials. However, our goal was to expand its original limited scope to be able to identify more than 200 other radioactive sources. As a result, at its inception, this expanded version of HPGe ID was plagued with frequently occurring misidentifications. For a period extending over nearly a decade we have reduced the frequency of misidentifications to the point that the application is now highly valued by its users. Nevertheless, HPGE ID continues to be a work in progress.

\section{Acknowledgements}

The HPGe ID application described in the beginning pages of this paper was the brainchild of Mark S. Rowland and was implemented in software by James L. Wong. In its original embodiment, HPGe ID was almost exclusively oriented to simple identification of 41 nuclides and mixed sources.

In late 2003, Rowland approached this paper's author with a request to extend the scope of the HPGe ID knowledge base to identify about 300 nuclides and mixed sources, with timely and invaluable programming assistance from James Wong. Additionally, a second goal was to considerably extend HPGe ID's source characterization capability, particularly of plutonium and uranium, with the latter characteristics being the subject of this paper.

The author would like to further express his appreciation for observations, contributions, encouragement, and support from Livermore Laboratory colleagues Jennifer Church, Daniel Decman, Daniel Dietrich, Phillip Kerr, Alexander Loshak, and Karl Nelson; David Mercer of the Los Alamos National Laboratory; and Professor Stanley Prussin of the University of California at Berkeley. 


\section{Appendix: Signal-to-noise ratio computation}

\section{Single-peak signal-to-noise ratio}

In this paper we refer to the ratio of net counts in a full-energy-peak to the underlying continuum counts, in units of local variance, as the signal-to-noise ratio for the net peak counts. For a peak to be declared manifest, its signal-to-noise ratio must exceed a detection threshold that, with rare exception, is set at 5 .

In Fig. A-1 the net counts in a photopeak are the difference of the gross counts in the spectral region of the photopeak minus the counts in the continuum below the photopeak. Although more sophisticated algorithms exist for determining the number of counts in the continuum below the peak, the simplest, and quite adequate for rough signal-to-noise estimation, is to approximate the continuum as a straight line. This leaves a quadrilateral shape under the peak that constitutes the noise in the measurement. The area of this quadrilateral is the product of its average height with the width of its base, the "resolution width" $R_{W}$ of the peak channels. To estimate the average height of the continuum in counts, we average the counts in the channels immediately neighboring $R_{W}$. We can use more than one channel on each side to increase the statistical quality of the estimate but if we use too many, any bias in the estimate will likely increase. Here we discuss using three neighboring channels on each side of the peak.

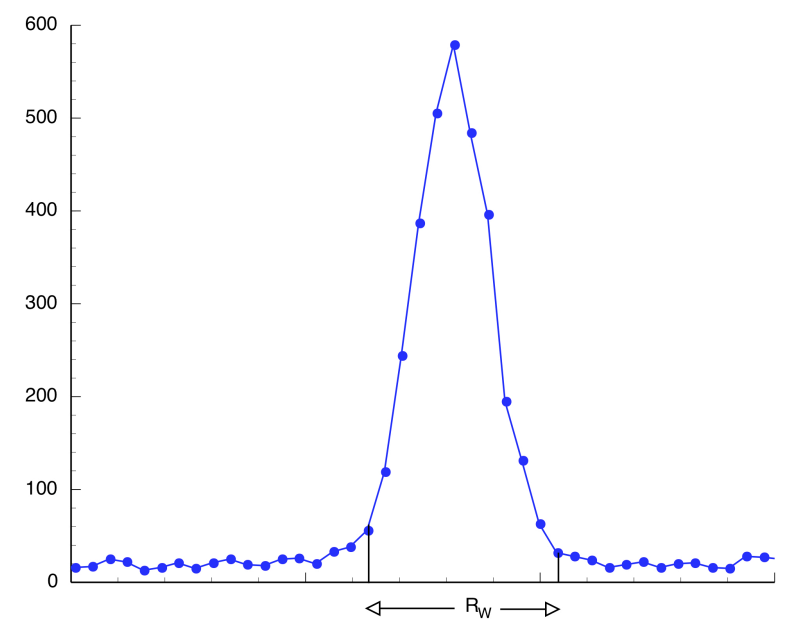

Fig. A-1. Schematic illustration of a photopeak (full-energy peak) resting on a continuum from ambient background radiation, downscatter from other source gamma rays, or selfactivity in the detector.

$$
N=\sum_{g=1}^{R_{W}} C_{g}-\frac{R_{W}}{6} \sum_{n=1}^{6} C_{n}
$$


Where $N$ is the net photopeak counts, the $C_{g}$ are the gross counts per channel in the $R_{W}$ channels in the resolution width of the photopeak, and the $C_{n}$ are the counts in the three neighboring channels in each side of the peak.

Assuming that the data acquisition time of the measurement is a small fraction of the half-lives of the source(s) measured, the counts in each channel will closely follow a Poisson probability distribution. The variance in a Poisson random variable is its mean and its standard deviation is the square root of the mean. If the number of counts is sufficiently large (say 20 or 30 or greater), we can make an acceptable estimate the mean for our uncertainty analysis purpose, by using the number of counts observed. The counts in each channel are statistically independent, so we can estimate the uncertainty in the net counts by simple propagation of errors [71], such that the estimated variance in a quantity $Q\left(x_{1}, x_{2}, \cdots, x_{p}\right)$ of $p$ variables is given by

$$
\sigma_{Q}^{2} \approx \sum_{i=1}^{p}\left\lfloor\sigma_{x_{i}}^{2}\left(\frac{\partial x_{i}}{\partial Q}\right)^{2}\right\rfloor
$$

Applying Eq. (A-2) to Eq. (A-1) gives

$$
\sigma_{N}^{2}=\sum_{g=1}^{R_{W}} C_{g}+\frac{R_{W}^{2}}{36} \sum_{n=1}^{6} C_{n}
$$

However, for small count values this estimate becomes biased because the Poisson distribution is bounded at zero and skewed. We can largely remove the bias by adding one to the count value to estimate an estimate the mean,

$$
E\left(\sigma^{2}\right) \approx C+1
$$

We note that both $\sum C_{g}$ and $\sum C_{n}$ are the sums of Poison random variable and are therefore Poisson random variables themselves. Adding one to each of these variables leads us to Eq. A-4

$$
\sigma_{N}^{2}=\left(\sum_{g=1}^{R_{W}} C_{g}\right)+1+\frac{R_{W}^{2}}{36}\left[\left(\sum_{n=1}^{6} C_{n}\right)+1\right]=\sum_{g=1}^{R_{W}} C_{g}+\frac{R_{W}^{2}}{36} \sum_{n=1}^{6} C_{n}+\left(1+\frac{R_{W}^{2}}{36}\right)
$$

We further note that Eq. A-1 is the difference between a Poisson random variable and a scaled Poisson ransom variable. While the sum of Poisson random variables is itself a Poisson random variable, this is not true for the difference of two Poisson random variables. For this reason, the final term in parentheses is likely an overestimate and a more likely value, $V$, would lie between two extremes.

$$
1<V<\left(1+\frac{R_{W}^{2}}{36}\right)
$$

But what value do we use? For quite a few years, we ignored the small value problem and used Eq. A-3. Our user experience indicated that, as a rule, setting a detection threshold of 5 from Eq. A-3 yielded well-differentiated and quite useful peak strength results. For this 
reason we have been loath to tinker excessively with the values obtained from Eq. A-3. Accordingly, we have chosen to implement a modified version of Eq. A-4 using the lower limit of 1 from Eq.-A-5.The photopeak signal-to-noise ratio is then

$$
\frac{N}{\sigma_{N}}=\frac{\sum_{g=1}^{R_{W}} C_{g}-\frac{R_{W}}{6} \sum_{n=1}^{6} C_{n}}{\sqrt{\sum_{g=1}^{R_{W}} C_{g}+\frac{R_{W}^{2}}{36} \sum_{n=1}^{6} C_{n}+1}}
$$

\section{Effective signal-to-noise ratios for provisional nuclide identification}

The provisional identification of individual nuclides requires the identification of one to four key individual manifest peaks. We refer to this as provisional because, at this stage, misidentification is possible. Further testing, involving the satisfaction of additional conditions, is usually required to result in a finding of nuclide presence. A Boolean logic chain, illustrated by the following three-peak example, determines the provisional presence or absence of a hypothetical nuclide $x$, from the provisional presence of three peaks.

IF peak-1 is manifest,

AND Peak-2 is manifest,

AND Peak-3 is manifest,

THEN nuclide $x$ is present,

ELSE nuclide $x$ is not manifest and assumed absent

In the rare instance when only a single substantial gamma ray is emitted, such as with ${ }^{137} \mathrm{Cs}$, the single-peak signal-to-noise ratio computed with Eq. A-6 suffices for the signal-to-noise ratio for the provisional nuclide identification. However for multiple peaks, a chain of logical ANDs is clearly not equivalent to an arithmetic sum. A rigorous approach to computing a signal-to-noise ratio in this case would require a complex probabilistic calculation that is beyond the scope of HPGe ID. It is clear, however, that the probability of correctly identifying a nuclide is increased when multiple peaks form its signature. Accordingly, we have, for an effective signal-to-nose estimation, treated provisional nuclide identification as an arithmetic net peak sum and calculated an effective signal-to-nose ratio for the nuclide.

The total net counts from multiple peaks, $T$, is the sum of the net counts from the $p$ individual peaks in the region of interest.

$$
T=\sum_{i=1}^{p} N_{i}
$$

The estimate of the variance associated with $T$ as the combination of the variances of the individual peaks taken in quadrature.

$$
\sigma_{T}^{2}=\sqrt{\sum_{i=1}^{p} \sigma_{N_{i}}^{2}}
$$


The total signal-to-noise ratio is then:

$$
T / \sigma_{T}
$$

\section{Effective signal-to-noise ratio for individual findings}

A Boolean chain of reasoning, also determines each of the detailed findings reported in the lower pane of the user interface Details window in Fig. 3. The first condition in each of these chains is the dominant signature. This will typically be the provisional nuclide identification or a ratio, as in the case of uranium enrichment estimates. These chains can be quite long, containing a mixture of logical ANDs and NOTs. This situation is fraught with even greater difficulty than estimating a signal-to-noise ratio for provisional nuclide identification. For this reason we simply report an effective signal-to-ratio estimate based only on the signal-to-noise ratio of the first condition.

\section{Confidence in the HPGe ID findings}

The HPGe ID findings are sorted by descending effective signal-to-noise ratio for display in the user interface. While the effective signal-to-noise ratio is not a rigorous statistical estimate of findings confidence, experience has shown that it has been an effective indication of relative signal strength.

HPGe ID is an automated, "blind" spectrum analysis, a challenging problem fraught with many potential pitfalls. Computing a rigorous statistical estimate of findings confidence is beyond the scope of HPGe ID's goal of providing the analyst with a very rapid qualitative assessment of the radionuclides present in an HPGe gamma-ray spectrum. Furthermore, a rigorous statistical confidence estimate would still be a part of a "blind" analysis and, in that sense, not much more believable than the effective signal-to-noise ratio. The purpose of the HPGe ID explanation facility is to free the analyst from total dependence on a "blind" analysis, reliant on mathematics, and provide the analyst with a visual spectral comparison with trusted spectral templates, a reliance on physics. 


\section{References}

1. Karl E. Nelson, Thomas B. Gosnell, David A. Knapp, The effect of energy resolution on the extraction of information content from gamma-ray spectra, Nucl. Instr. Meth. Phys. Research A 659 (2011) 207.

2. Glenn F. Knoll, Radiation Detection and Measurement, Third Ed., Wiley, New York 2000, p. 428.

3. Artificial Intelligence, Rule-based expert systems, http: intelligence.worldofcomputing.net/expert-systems-articles/rule-based-expertsystems.html

4. Adrian A Hopgood, Intelligent Systems for Engineers and Scientists, $2^{\text {nd }}$ Ed., CRC Press, pp 1-47, New York, 2001.

5. U.S. Environmental Protection Agency, About TENORM, http://www.epa.gov/rpdweb00/tenorm/about.html

6. U.S. Environmental protection agency, Technologically-Enhanced, Naturally-Occurring Radioactive Materials, http://www.epa.gov/radiation/tenorm/

7. U.S. Environmental protection agency, TENORM in consumer products, http://www.epa.gov/radiation/tenorm/consumer.html

8. A. Barr and E. A. Eigenbaum, The Handbook of Artificial Intelligence, vol. 1, AddisonWesley, 1986.

9. Wikipedia, Abundance of elements in the Earth's crust, http: en.wikipedia.org/wiki/Abundance of elements in Earth\%27s crust

10. The University of Sheffield and WebElements Ltd, Abundance in Earth's crust, UK, http://www.webelements.com/periodicity/abundance crust/

11. Jefferson Lab, It's Elemental-The Periodic Table of the Elements, http://education.jlab.org/itselemental/index.html

12. Atomic weights of the elements: Review 2000, Pure Appl. Chem., Vol. 75, No. 6, p. 787, 2003 (IUPAC Technical Report), http://pac.iupac.org/publications/pac/pdf/2003/pdf/7506x0683.pdf

13. Y. Fujikawa, M. Fukui, M. Sugahara, E. Ikeda and M. Shimada Y. Fujikawa1, M. Fukui, M. Sugahara, E. Ikeda and M. Shimada, Variation in uranium isotopic ratios ${ }^{234} U{ }^{238} U$ and ${ }^{235} \mathrm{U} /$ total-U in Japanese soil and water samples - Application to environmental monitoring, International Radiation Protection Association, http://www.irpa.net/irpa10/cdrom/00809.pdf

14. Mineral and locality database, http://www.mindat.org/.

15. Mineralogy Database, http://webmineral.com/cgibin/search/search.pl?Realm=All\&Match=1\&Terms=uranium\%20ore \&maxhits=10\&Rank=1

16. Wikipedia, Uranium ore, http://en.wikipedia.org/wiki/Uranium ore.

17. Feature stories: Depleted uranium, International Atomic Energy Agency, Vienna, http://www.iaea.org/newscenter/features/du/du qaa.shtml

18. Argonne National Laboratory, Chemical forms of uranium, http://web.ead.anl.gov/uranium/guide/ucompound/forms/index.cfm

19. Richard L. Meyers, The 100 most important chemical compounds: a reference guide, Greenwood Press, Westport, Connecticut, , p. 2852007.

20. Britannica Online Encyclopedia, Uraninite (mineral), http://www.britannica.com/EBchecked/topic/619106/uraninite

21. U. S. Nuclear Regulatory Commission, NRC regulations $\$ 110.2$ Definitions, http://www.nrc.gov/reading-rm/doc-collections/cfr/part110/part110-0002.html

22. Wikipedia, Weapons-grade, http://en.wikipedia.org/wiki/Weapons-grade 
23. Frank Settle, Nuclear Chemistry: Uranium Enrichment, General Chemistry Case Studies, http://www.chemcases.com/nuclear/nc-07.html

24. Morten Bremer Maerli, Components of naval nuclear fuel transparency, Norwegian Institute of International Affairs, p. 26, 2002, http://www.nato.int/acad/fellow/99-01/maerli.pdf

25. Wikipedia, Reprocessed uranium, January 2012, http://en.wikipedia.org/wiki/Reprocessed_uranium

26. Mary Byrd Davis, Uranium from reprocessing (REPU), Nuclear France: Materials and Sites, http://www.francenuc.org/en mat/uranium4_e.htm

27. World Nuclear Association, Processing of Used Nuclear Fuel, May 2012, http://world-nuclear.org/info/inf69.html

28. Alan P. Dickin, Radiogenic Isotope Geology, $2^{\text {nd }}$ Ed., Cambridge University Press, Cambridge, UK, 2005, p. 324.

29. U. S. Department of Energy, Plutonium: The First 50 Years, DOE/DP-0137, 1996, http://www.doeal.gov/SWEIS/DOEDocuments/004\%20DOE-DP0137\%20Plutonium\%2050\%20Years.pdf

30. Argonne National Laboratory, Uranyl Fluoride, http://web.ead.anl.gov/uranium/guide/ucompound/propertiesu/fluoride.cfm

31. P. Bossew, A very long-term HPGe-background gamma spectrum, Applied Radiation and Isotopes 62 (2005) 635.

32. Radium-Human Health Fact Data Sheet, Environmental Assessments Division, Argonne National Laboratory, 2005, http://www.evs.anl.gov/pub/doc/radium.pdf.

33. Ibid. ref. 2, p 450.

34. Edgardo Browne and Richard B. Firestone, with Virginia S. Shirley, Editor, Table of Radioactive isotopes, John Wiley and Sons, New York, (1986).

35. C. W. Forsberg, C. M. Hopper, and H. C. Vantine, Definition of weapons-usable uranium233, Oak Ridge National Laboratory report ORNL/TM-13517, 1998. http://www.ornl.gov/sci/radiation transport criticality/HopperPubs/DefWeaponsUsableU233ORNLTM13517.pdf

36. Gordon R. Gilmore, Practical Gamma-ray Spectrometry, $2^{\text {nd }}$ Ed., Wiley, Hoboken, NJ, 2008, p. 319.

37. Wikipedia, Uranium-234, http://en.wikipedia.org/wiki/Uranium-234

38. IAEA NAPC Physics Section, WIMS Library Update Project, Actinides burnup chain, http://www-nds.iaea.org/wimsd/achain.htm

39. Wikipedia, Thorium fuel cycle, http://en.wikipedia.org/wiki/Thorium fuel cycle

40. J. Kang and F. N. von Hippel, U-232 and the Proliferation-Resistance of U-233 in Spent Fuel, Science \& Global Security, 9 pp 1-32.

41. International Thorium Energy Organisation, Stockholm, Sweden, http://www.itheo.org.

42. Charles Barton, Thorium fuel cycle development in India, EnergyFromThorium, http://energyfromthorium.com/2008/04/15/thorium-fuel-cycle-development-in-india/

43. Koyel X. Bhattacharyya, India advances thorium breeding technology, Stanford energy journal, http://energyclub.stanford.edu/index.php/Journal/India Advances Thorium Breeding Techn ology by Koyel Bhattacharyya, Spring 2012.

44. Neelima Prasad, Anek Kumar, Umasankari Kannan, Arvind Kumar, P.D. Krishnani, R.K. Sinah, Study for use of LEU along with Thorium in Advanced Heavy Water Reactor (AHWR) 
to Enhance Proliferation Resistance Characteristics of Fuel, IAEA Paper Number: IAEACN-184/207.

45. Wikipedia, Uranium-236, http://en.wikipedia.org/wiki/Uranium-236

46. Nuclear Engineering International, GNEP is dead; long live Gen-4, July 2009, http://www.neimagazine.com/story. asp? storyCode $=2053466$

47. Nuclear Engineering International, DOE releases GNEP plan, January 2007, http://www.neimagazine.com/story.asp?storyCode $=2041507$

48. Ronald J. Ellis, Prospects of Using Reprocessed Uranium in CANDU Reactors, in the US GNEP Program, Oak Ridge National Laboratory,

2007,http://www.ornl.gov/sci/scale/pubs/ldoc7152 ans national summary nov2007 rje.pdf

49. Ahlmad Ibrahim and Kyle Oliver, Reactor physics analysis of the effects of U-236 poisoning on the use of reprocessed uranium in PWR fuel, Oak Ridge National Laboratory, 2007, http://kyleoliver.net/work/406 final.pdf

50. Stephan R. Winkler, Investigating ocean currents using uranium-236 from the 1960s, Medienportal, Universität Wein, December 2012.

http://medienportal.univie.ac.at/presse/aktuelle-

pressemeldungen/detailansicht/artikel/erforschung-von-meeresstroemungen-mit-uran-236aus-den-1960er-jahren-kopie-1/

51. Stephan R. Winkler, Peter Steier, and Jessica Carilli, Bomb fall-out ${ }^{236} U$ as a global oceanic tracer using an annually resolved coral core, Earth and Planetary Science Letters, 359-360, December 2012, pp. 124-130. http://www.sciencedirect.com/science/article/pii/S0012821X12005638

52. Peter Weiss, Science News, Vol. 162 \#17, p. 259, 2002, Neptunium Nukes? Little-studied metal goes critical, October 2002, http://www.webcitation.org/6Cw9Vnt0Q

53. Robert G. Lanier, Catherine F. Hayden, DeLynn Clark, and Winifred E. Parker, Evaluations of the ${ }^{35} \mathrm{U}^{238} \mathrm{U}$ isotope ratio through thick-walled containers using the 185.7-keV and 1001.0keV gamma rays, Lawrence Livermore National Laboratory report, UCRL-ID-143390 (2001).

54. R. Gunnink, W. D. Ruhter P. Miller, J. Goerten, M. Swinhoe, H. Wagner, J. Verplancke, and S. Abousahl, MGAU A New Analysis Code for Measuring U-235 Enrichments in Arbitrary samples, Lawrence Livermore National Laboratory Report, UCRL-JC-114713 Preprint, http://www.osti.gov/bridge/servlets/purl/10123137-zU1iH9/native/10123137.pdf, 1994.

55. Thomas B. Gosnell, Automated calculation of photon source emission from arbitrary mixtures of naturally radioactive heavy nuclides, Nucl. Instr. Meth. Phys. Research, A299 (1990) 682.

56. U.S. Department of Energy, New Brunswick Laboratory, http://www.nbl.doe.gov/htm/certified_reference_materials.htm

57. T.S. Zaritskaya, S.M. Zaritskii, A.K. Kruglov, L.V. Matveev, A.P. Rudik, and E.M. Tsenter, Atomnaya Energiya, 48 (1980) 67.

58. A.J. Perrung, PNNL-12075, Predicting ${ }^{232}$ U Content in Uranium, Pacific Northwest National Laboratory, Richland, WA, (1998).

59. T. B. Gosnell and B. A. Pohl, Spectrum synthesis-High-precision, high-accuracy calculation of HPGe pulse-height spectra from thick actinide assemblies, Lawrence Livermore National Laboratory report, UCRL-JC-120585, 1995.

60. Breismeister, J. F., (editor), Nov. 1993, MCNP-A General Monte Carlo N-Particle Transport Code, Version 4A, LA_12625-M, Los Alamos National Laboratory, 3-90.

61. D. J. Mitchell, H. M. Sanger, and K. W. Marlow, Gamma-ray response functions for scintillation and semiconductor detectors, Nucl. Instr. and Meth. A276 (1989) 547. 
62. IAEA Safeguards Glossary, 2001 Edition, International Nuclear Verificipn Series No. 3, International Atomic Energy Agency, p. 23, Vienna, 2002. http://wwwpub.iaea.org/MTCD/publications/PDF/nvs-3-cd/PDF/NVS3_prn.pdf

63. Health Physics Society, Answer to Question \#1593 Submitted to "Ask the Experts," http://www.hps.org/publicinformation/ate/q1593.html

64. Mary Lou Curtis, Determination of parts-per-million quantities of plutonium-236 in plutonium-238, Analytical Chemistry, 40 (8), 1968, p. 1352.

65. U. S. Department of Energy, Powering Curiosity: Lab Tech Goes to Mars, http://energy.gov/articles/powering-curiosity-lab-tech-goes-mars, 2012

66. Los Alamos National Laboratory, Nuclear powered cardiac pacemakers, http://osrp.lanl.gov/pacemakers.shtml.

67. David Prutchi, Nuclear Pacemaker-s, 2005, http://home.comcast.net/ dprutchi/nuclear pacemakers.pdf

68. V. Parsonnet, J. Didller, D. Cook, SA, Rizvi, Thirty-one years of clinical experience with "nuclear-powered" pacemakers, PubMed.gov, Pacing Clin Electrophysiol, 2006 Feb; 29(2), 195, http://www.ncbi.nlm.nih.gov/pubmed/16492308

69. U. S. Department of energy, Plutonium pellet, image in the public domain. http://commons.wikimedia.org/wiki/File:Plutonium_pellet.jpg

70. J. E. Jones, Jr., Process for producing ultra-pure plutonium-238, U. S. Patent number: 6896716, 2002, http://www.google.com/patents?vid=USPAT6896716

71. P.R. Bevington and D.K. Robinson, Data reduction and error analysis for the physical sciences, McGraw-Hill, Boston, $3^{\text {rd }}$ Ed., pp. 39-41, 2003. 